\title{
Supporting Information: Electrocatalytic Alcohol Oxidation with Iron-Based Acceptorless Alcohol Dehydrogenation Catalyst
}

\author{
Elizabeth A. McLoughlin ${ }^{1}$, Benjamin D. Matson ${ }^{1,2}$, Ritimukta Sarangi², and Robert M.
}

$$
\text { Waymouth }^{1 *}
$$

${ }^{1}$ Department of Chemistry, Stanford University, Stanford, CA 94305

${ }^{2}$ Stanford Synchrotron Radiation Lightsource, SLAC National Accelerator Laboratory, Menlo Park, California 94025

Corresponding Author: waymouth@stanford.edu

\section{Contents}

Additional cyclic voltammograms

Chemical oxidation studies

Controlled potential electrolysis

studies

X-ray absoprtion spectra

EXAFS FEFF best fits

DFT calculations 


\section{Additional Cyclic Voltammograms}

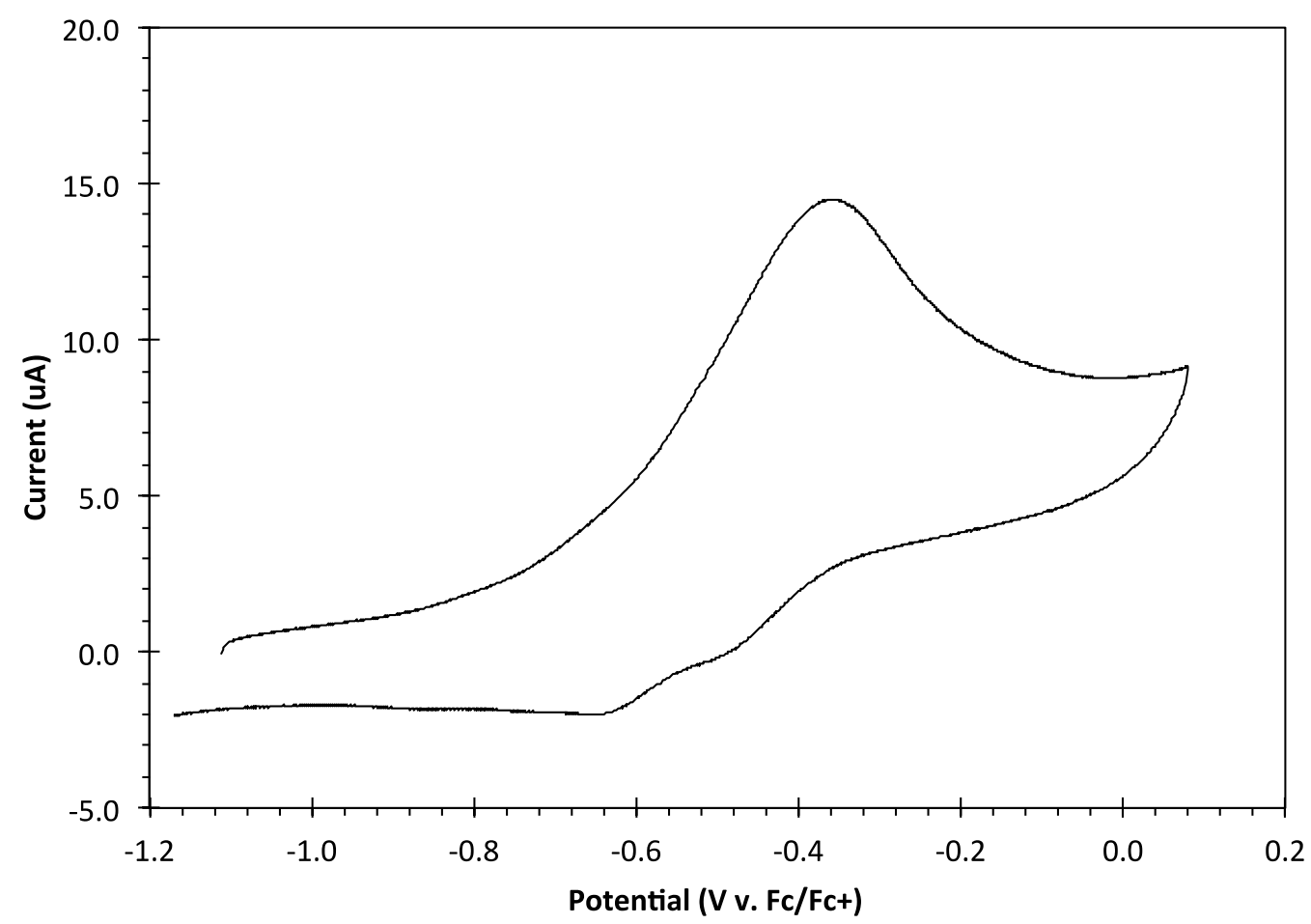

Figure S1. Cyclic voltammogram of FeN $1(1 \mathrm{mM})$ in $0.1 \mathrm{M} \mathrm{Bu}_{4} \mathrm{NBF}_{4}$ in tetrahydrofuran at 100 $\mathrm{mV} / \mathrm{s}$.

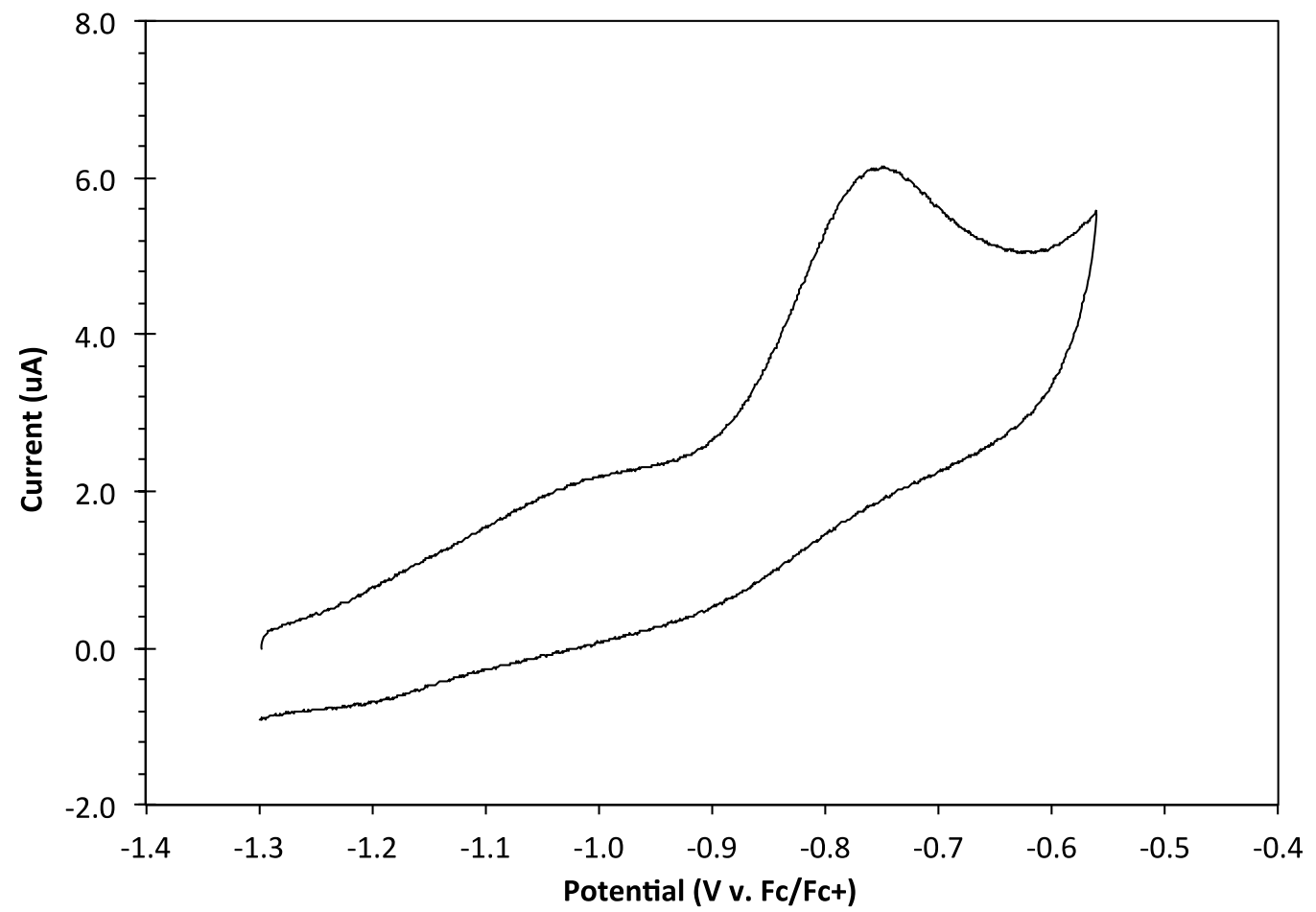

Figure S2. Cyclic voltammogram of $\mathrm{Fe}(\mathrm{H})(\mathrm{NH}) 2(1 \mathrm{mM})$ in $0.1 \mathrm{M} \mathrm{Bu}_{4} \mathrm{NBF}_{4}$ in tetrahydrofuran at $100 \mathrm{mV} / \mathrm{s}$. 


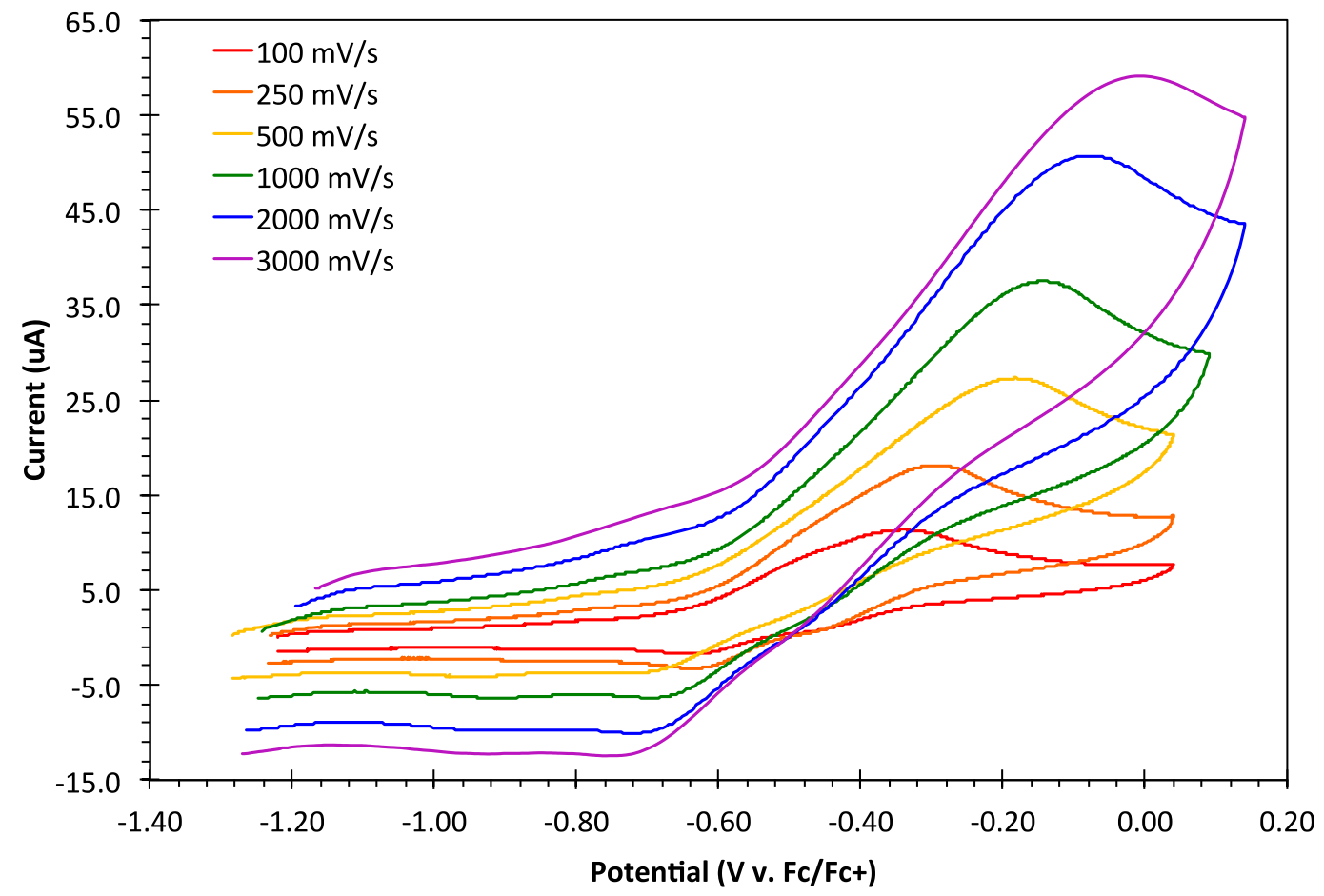

Figure S3. Cyclic voltammograms of FeN $1(1 \mathrm{mM})$ in $0.1 \mathrm{M} \mathrm{Bu}_{4} \mathrm{NBF}_{4}$ in tetrahydrofuran at various scan rates.

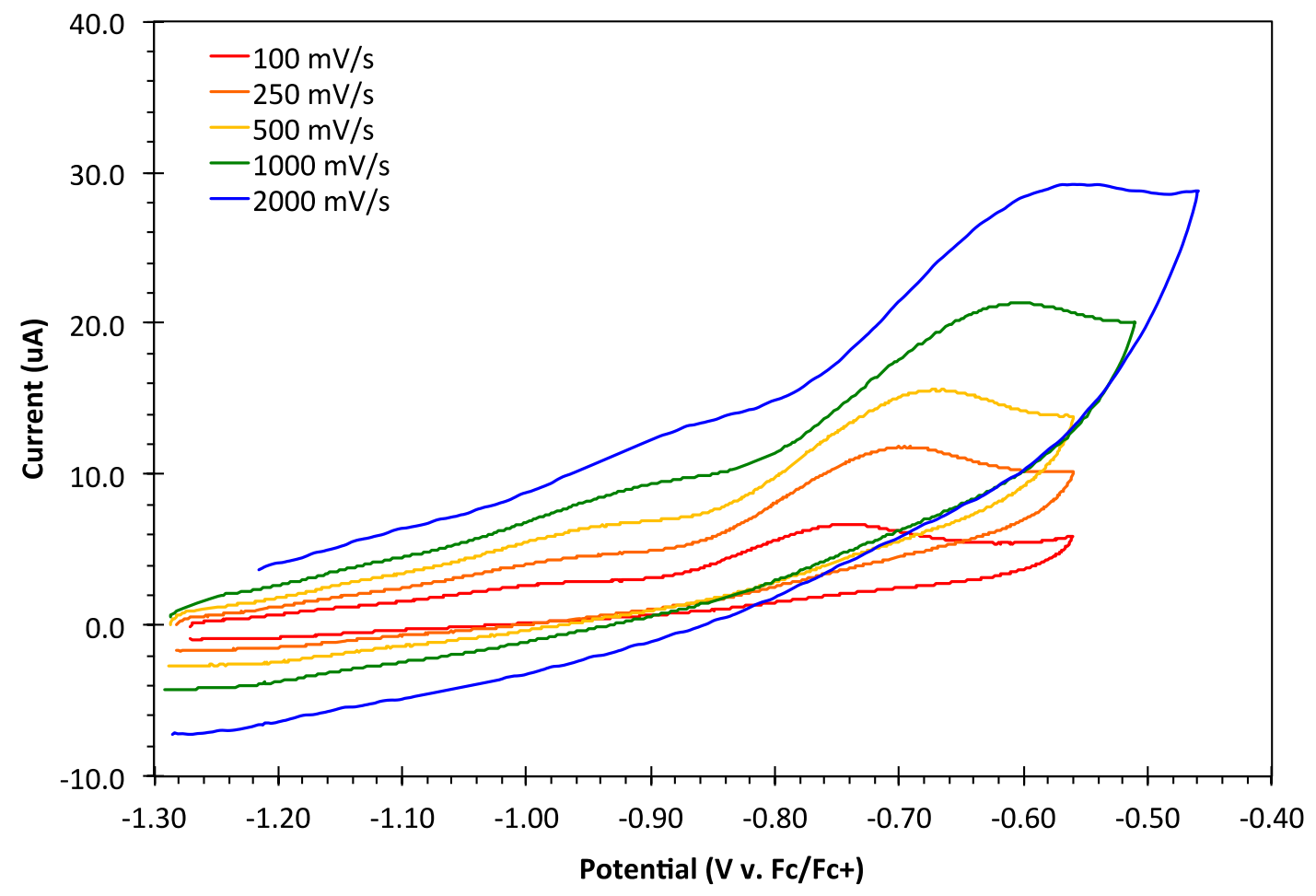

Figure S4. Cyclic voltammograms of $\mathrm{Fe}(\mathrm{H})(\mathrm{NH}) \quad \mathbf{2}(1 \mathrm{mM})$ in $0.1 \quad \mathrm{M} \quad \mathrm{Bu}_{4} \mathrm{NBF}_{4}$ in tetrahydrofuran at various scan rates. 


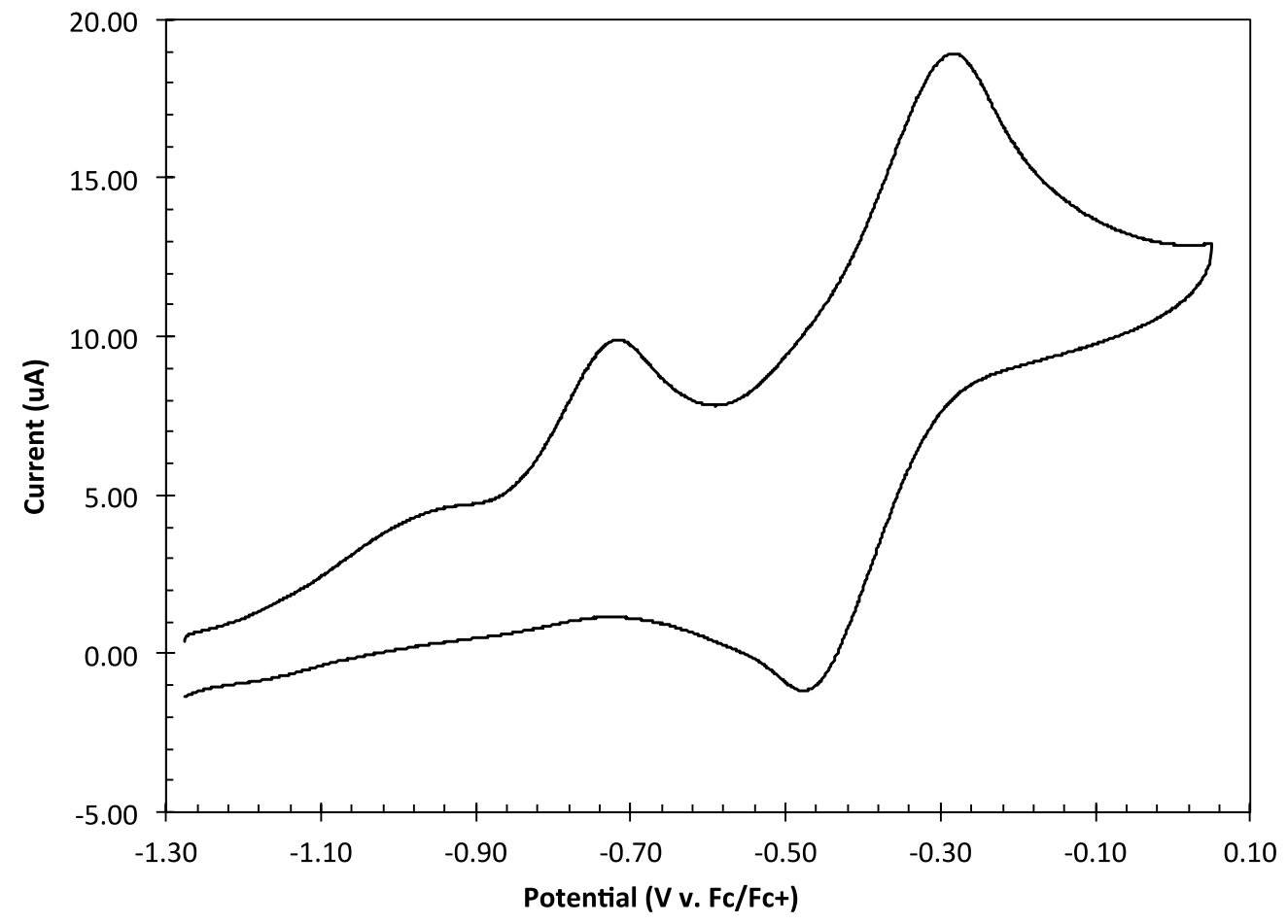

Figure S5. Long range cyclic voltammogram of $\mathrm{Fe}(\mathrm{H})(\mathrm{NH}) 2(1 \mathrm{mM})$ in $0.1 \mathrm{M} \mathrm{Bu}_{4} \mathrm{NBF}_{4}$ in tetrahydrofuran at $100 \mathrm{mV} / \mathrm{s}$.

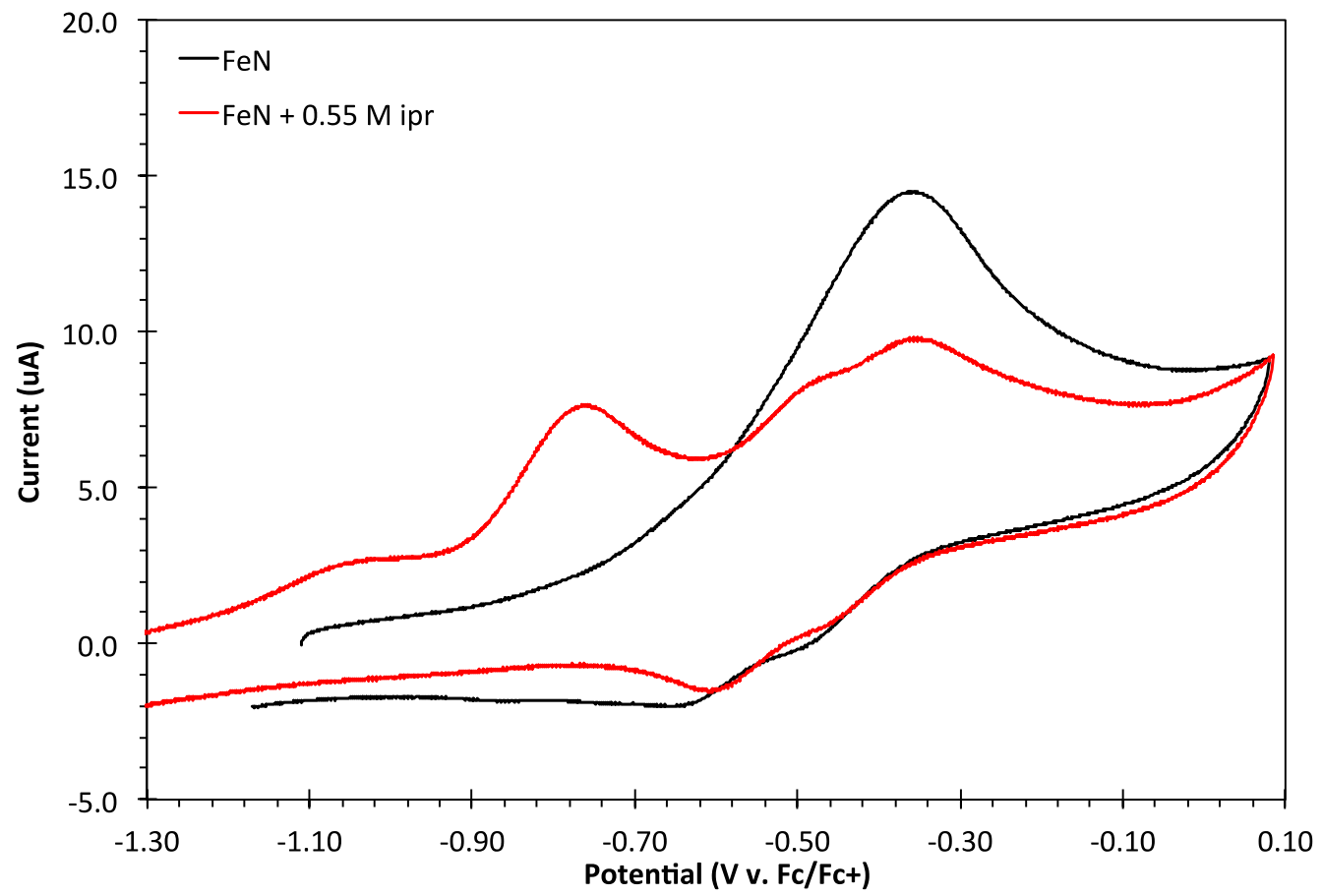

Figure S6. Cyclic voltammogram of FeN 1 (1 mM, black trace) in $0.1 \mathrm{M} \mathrm{Bu}_{4} \mathrm{NBF}_{4}$ in tetrahydrofuran followed by addition of isopropanol $(0.55 \mathrm{M}$, red trace) at $100 \mathrm{mV} / \mathrm{s}$. 


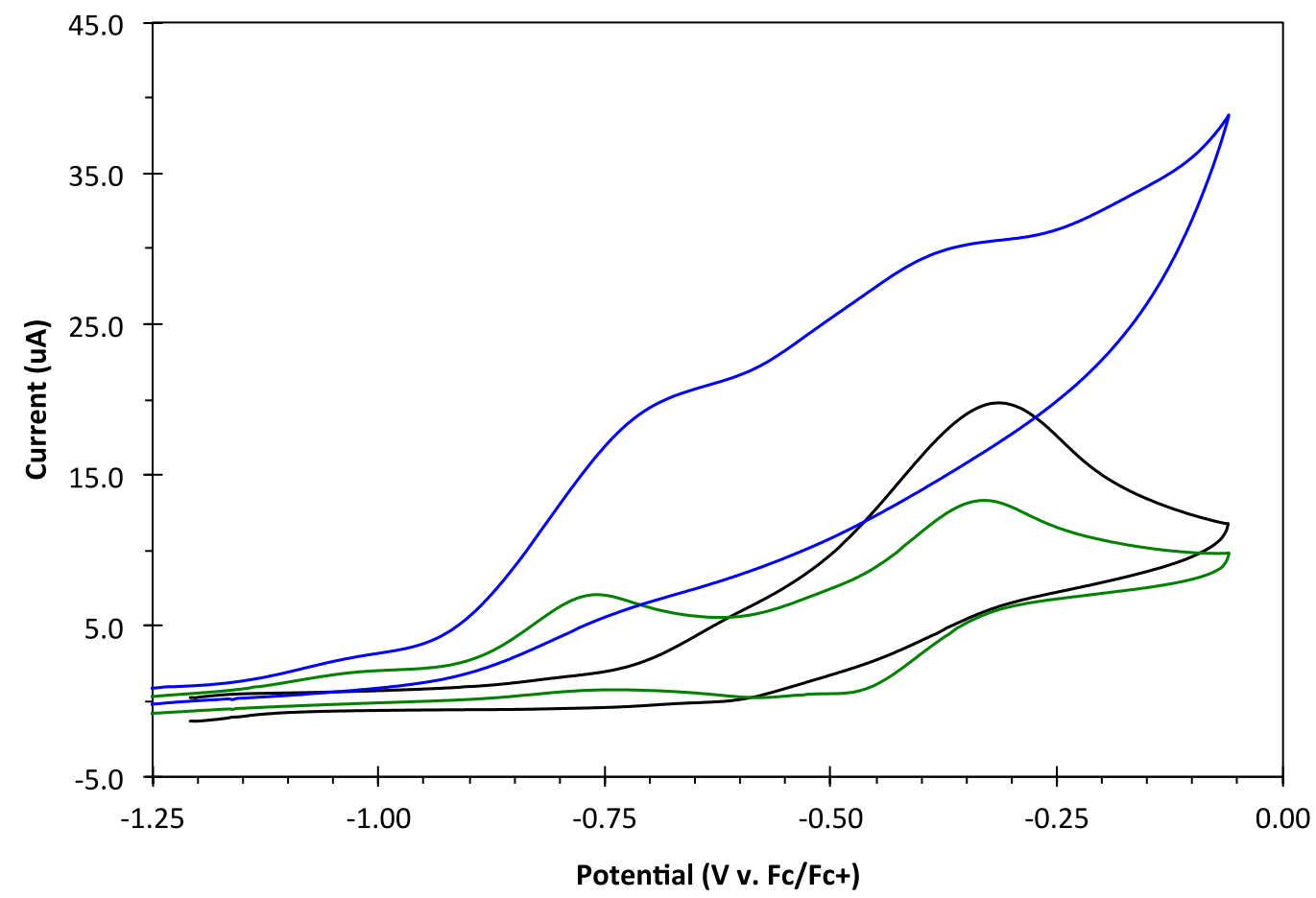

Figure S7. Cyclic voltammograms of FeN $1(1 \mathrm{mM})$ in $0.1 \mathrm{M} \mathrm{Bu}_{4} \mathrm{NBF}_{4}$ in tetrahydrofuran (black trace) with $0.5 \mathrm{M}$ isopropanol (green trace) and $11 \mathrm{mM}$ phosphazene base $\mathrm{P}_{2}$-Et (blue trace). Scan rate $100 \mathrm{mV} / \mathrm{s}$.

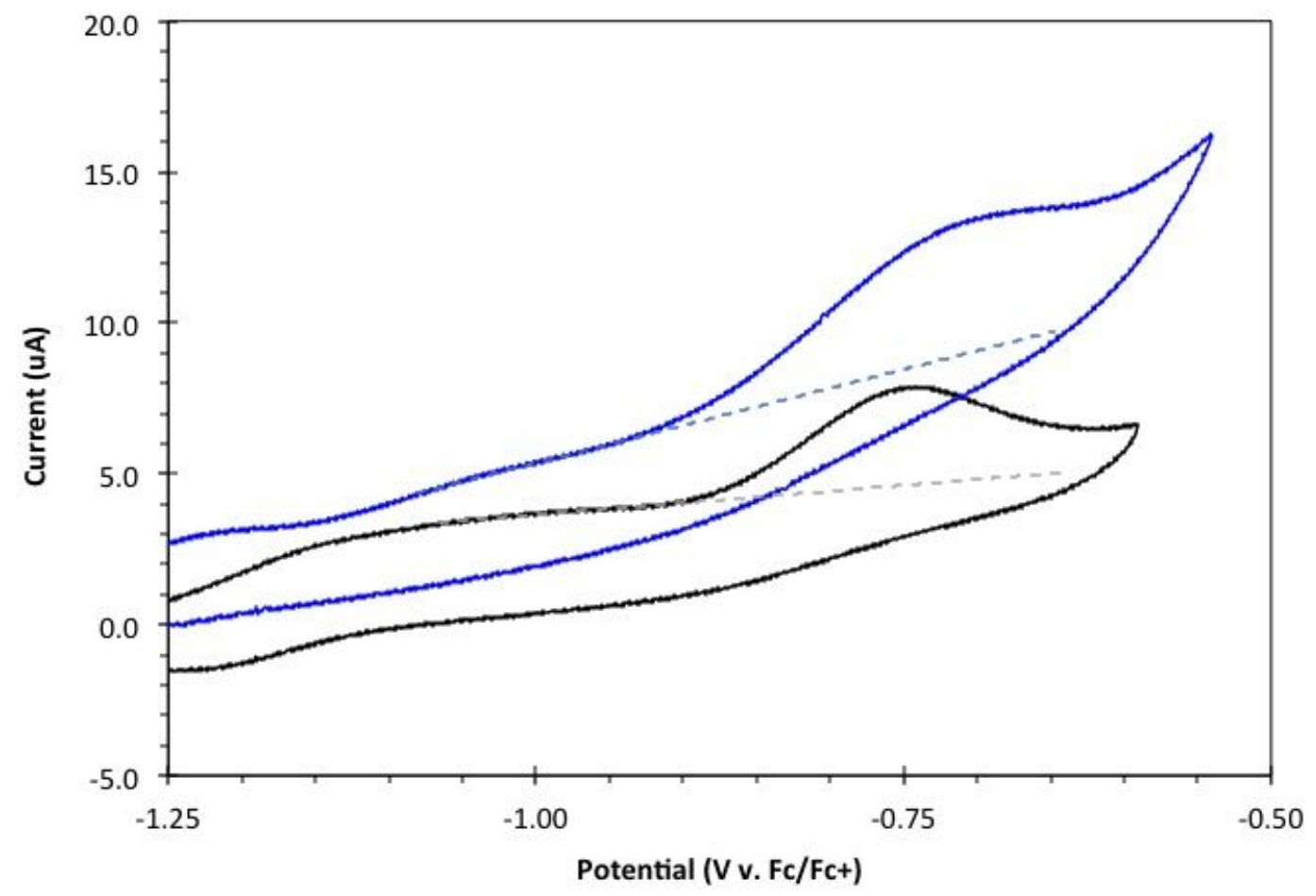

Figure S8. Cyclic voltammogram of $\mathrm{Fe}(\mathrm{H})(\mathrm{NH}) 2\left(0.7 \mathrm{mM}\right.$, black trace) in $0.1 \mathrm{M} \mathrm{Bu}_{4} \mathrm{NBF}_{4}$ in tetrahydrofuran followed by addition of phosphazene base $\mathrm{P}_{2}$-Et $(\mathrm{P} 2,3 \mathrm{mM}$, blue trace) at 100 $\mathrm{mV} / \mathrm{s}$. 


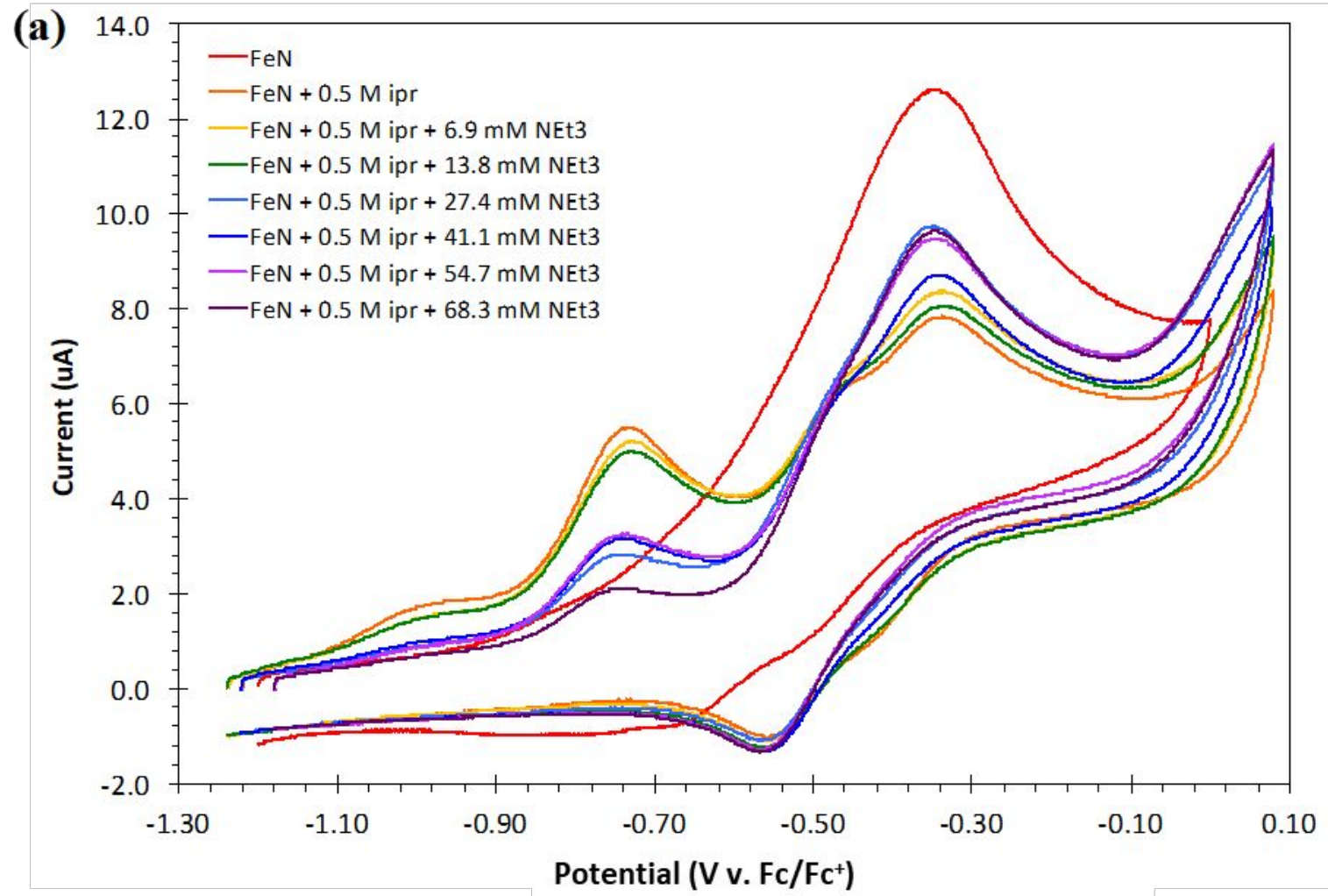

(b)

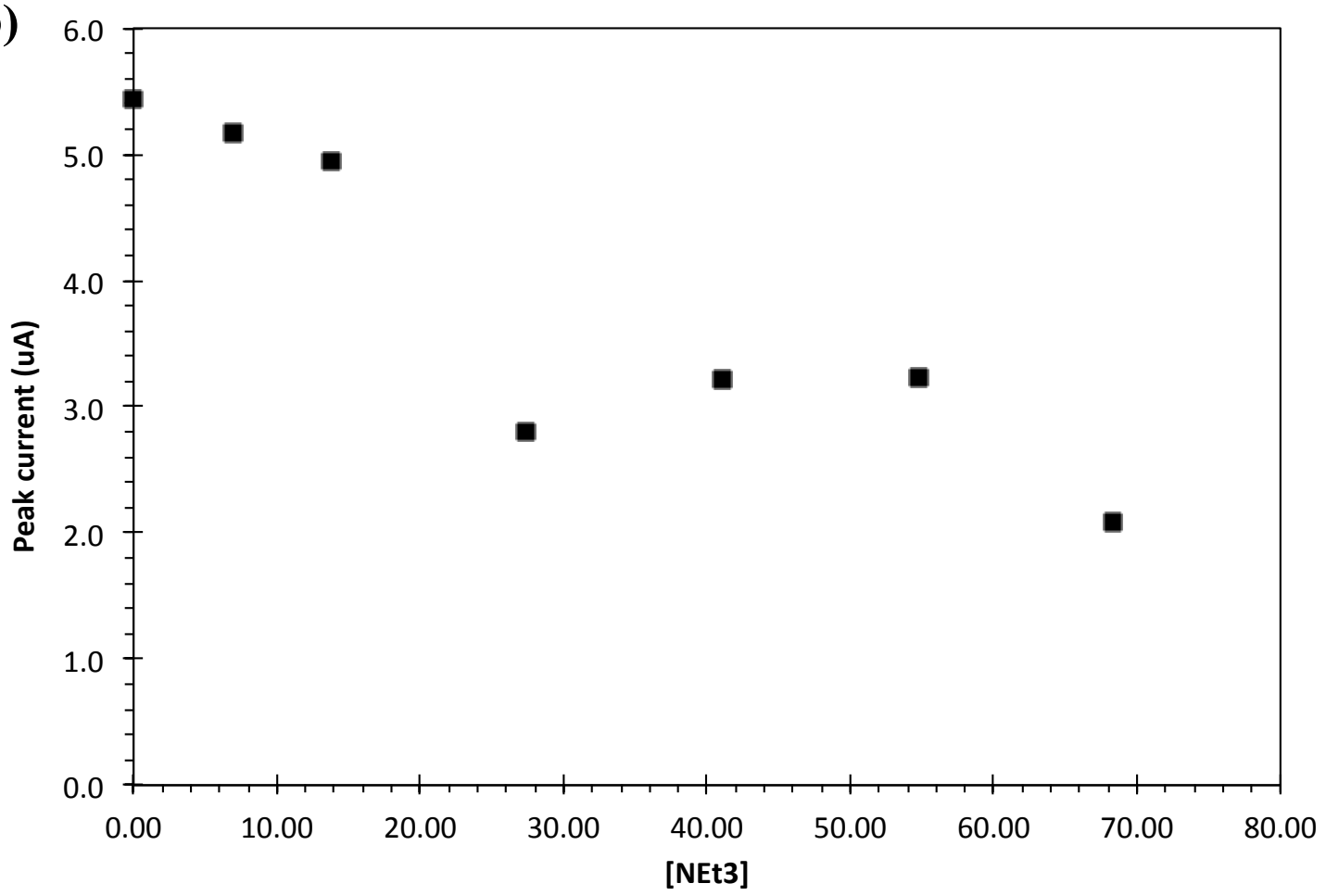


Figure S9. (a) Cyclic voltammograms of $\mathrm{FeN} 1\left(1 \mathrm{mM}\right.$, red trace) in $0.1 \mathrm{M} \mathrm{Bu}_{4} \mathrm{NBF}_{4}$ in tetrahydrofuran followed by addition of isopropanol $(0.5 \mathrm{M}$, orange trace) and titration of triethylamine at $100 \mathrm{mV} / \mathrm{s}$. (b) $\left[\mathrm{NEt}_{3}\right]$ dependence on the peak current at $-0.74 \mathrm{~V} \mathrm{v} . \mathrm{Fc}^{0 /+}$.

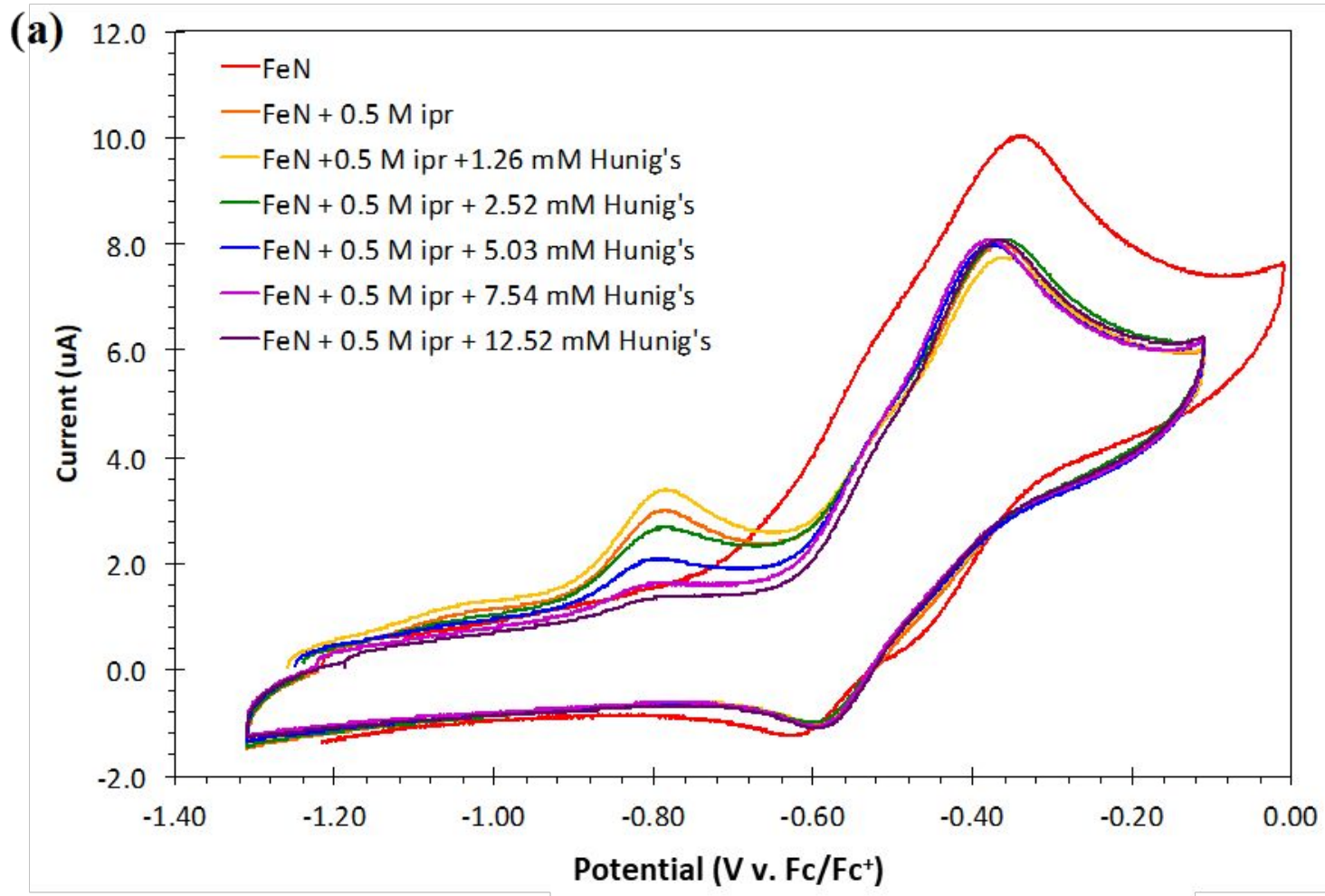

(b)

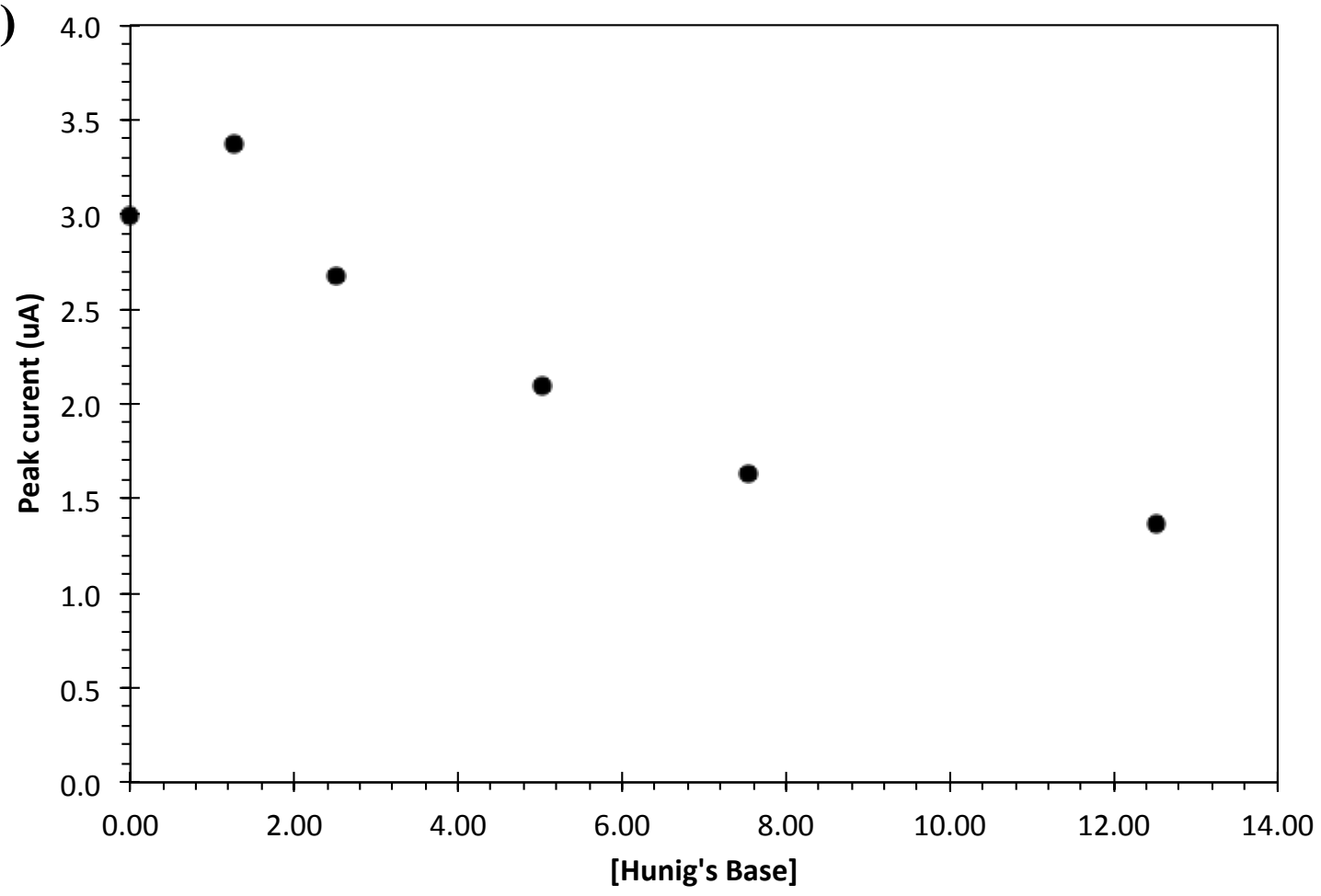


Figure S10. (a) Cyclic voltammograms of FeN $1\left(1 \mathrm{mM}\right.$, red trace) in $0.1 \mathrm{M} \mathrm{Bu}_{4} \mathrm{NBF}_{4}$ in tetrahydrofuran followed by addition of isopropanol $(0.5 \mathrm{M}$, orange trace) and titration of Hunig's base at $100 \mathrm{mV} / \mathrm{s}$. (b) [Hunig's base] dependence on the peak current at $-0.74 \mathrm{~V} \mathrm{v}$. $\mathrm{Fc}^{0 /+}$.
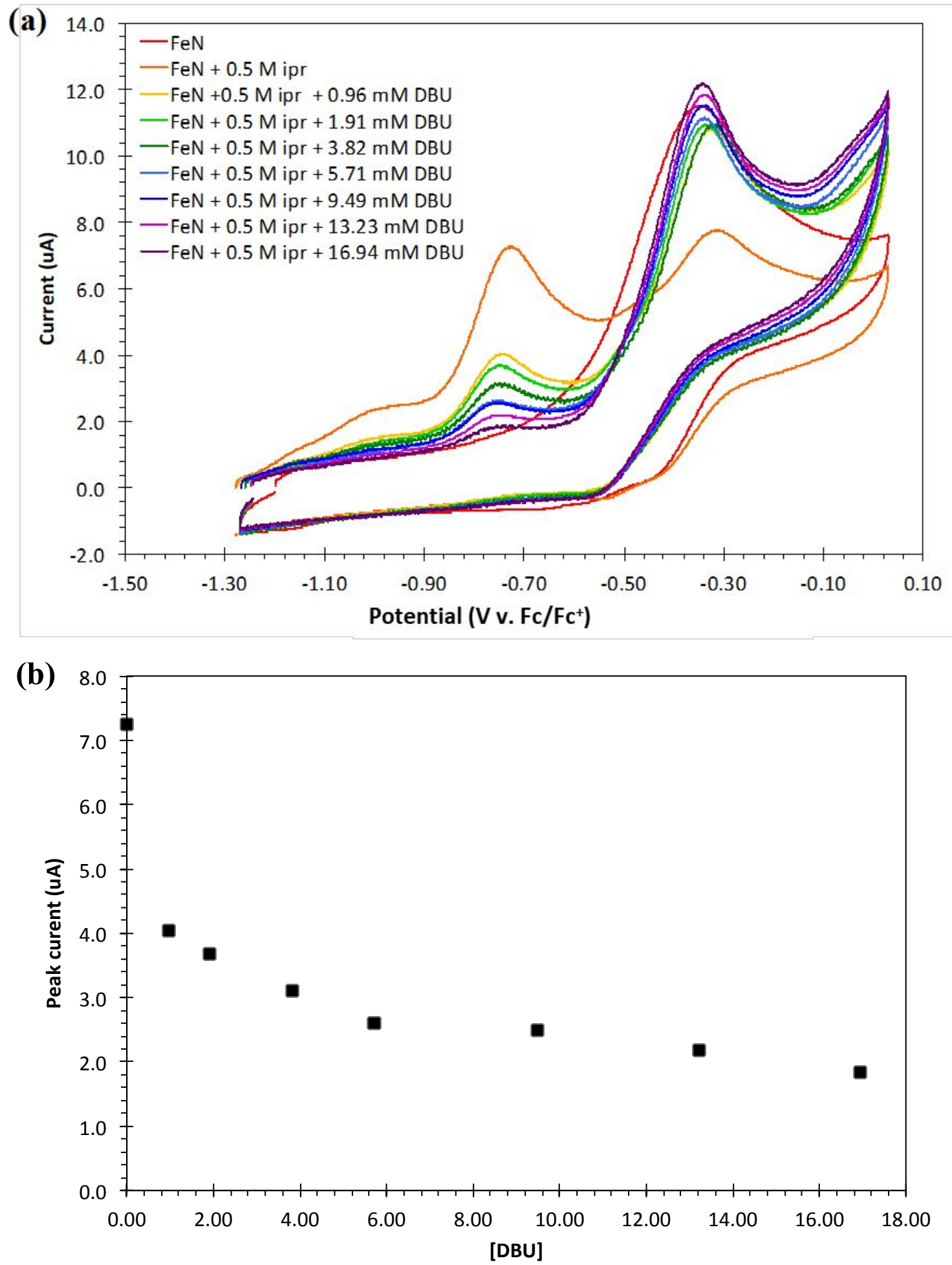

Figure S11. (a) Cyclic voltammograms of FeN $1\left(1 \mathrm{mM}\right.$, red trace) in $0.1 \mathrm{M} \mathrm{Bu}_{4} \mathrm{NBF}_{4}$ in tetrahydrofuran followed by addition of isopropanol $(0.5 \mathrm{M}$, orange trace) and titration of 1,8 - 
diazabicyclo[5.4.0]undec-7-ene (DBU) at $100 \mathrm{mV} / \mathrm{s}$. (b) [DBU] dependence on the peak current at $-0.74 \mathrm{~V} \mathrm{v} . \mathrm{Fc}^{0 /+}$.
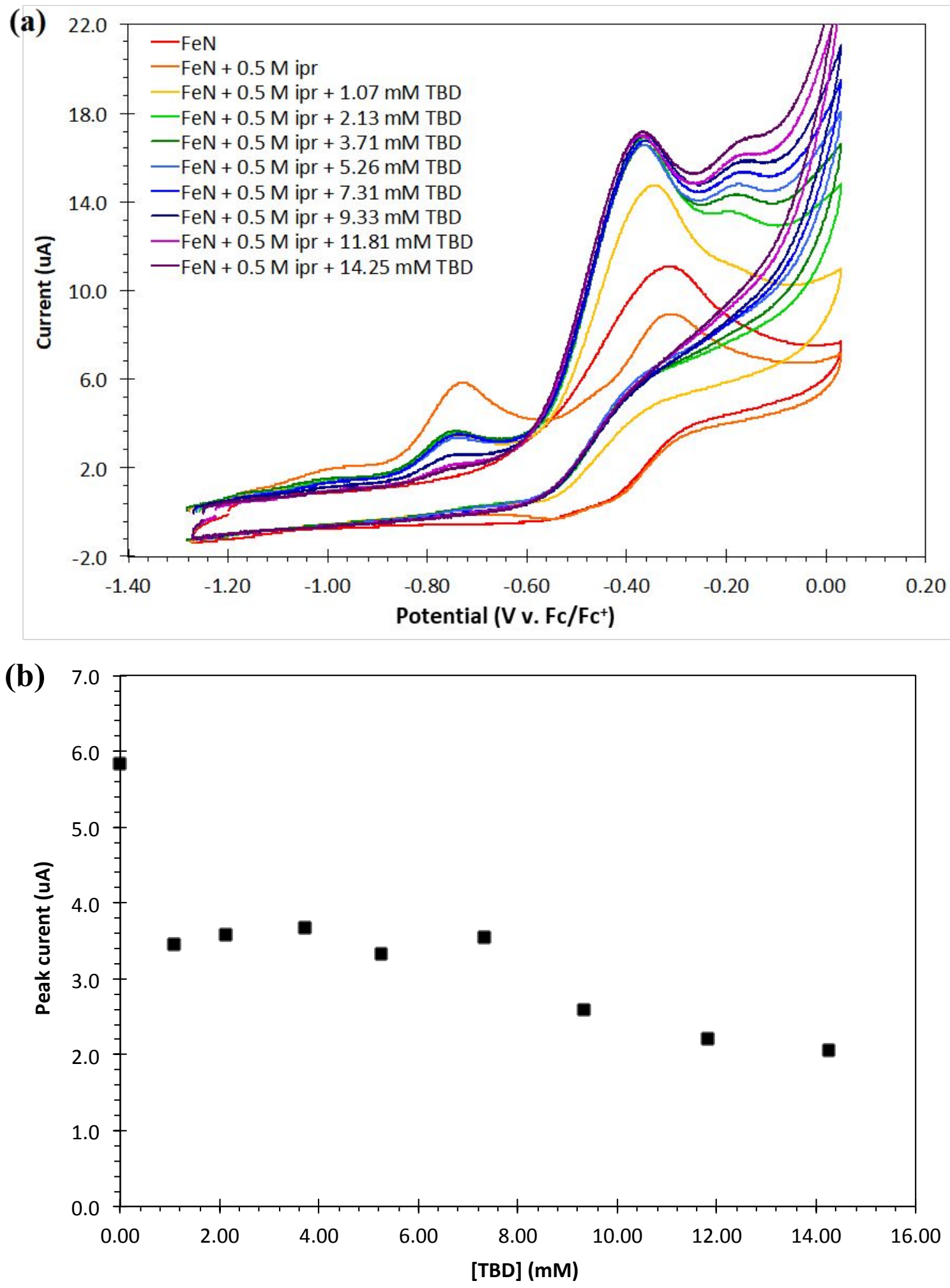

Figure S12. (a) Cyclic voltammograms of FeN $1\left(1 \mathrm{mM}\right.$, red trace) in $0.1 \mathrm{M} \mathrm{Bu}_{4} \mathrm{NBF}_{4}$ in tetrahydrofuran followed by addition of isopropanol $(0.5 \mathrm{M}$, orange trace) and titration of 
triazabicyclodecene (TBD) at $100 \mathrm{mV} / \mathrm{s}$. (b) [TBD] dependence on the peak current at $-0.74 \mathrm{~V}$. $\mathrm{Fc}^{0 /+}$.

(a)

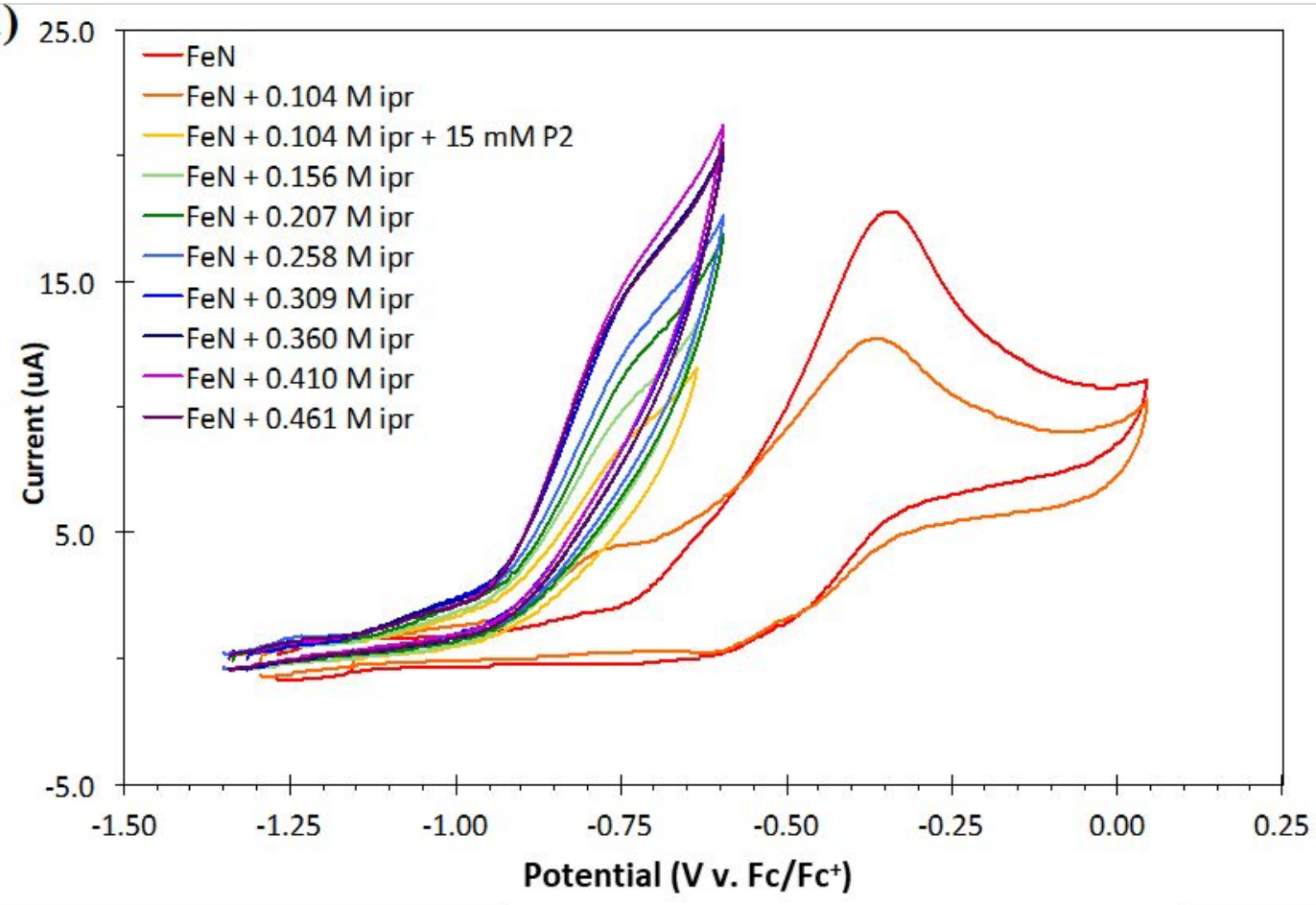

(b)

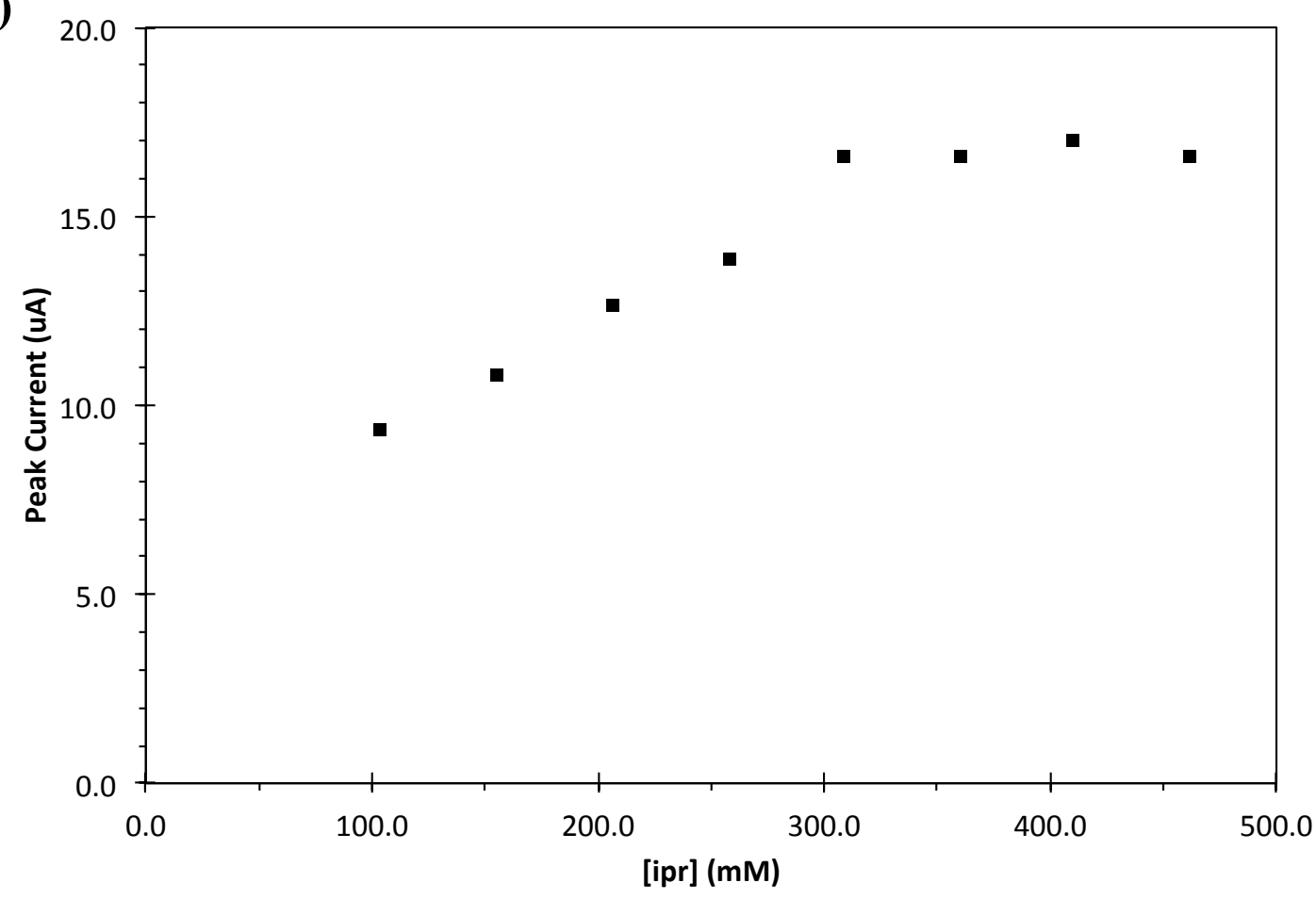

Figure S13. (a) Cyclic voltammograms of FeN $1(1 \mathrm{mM})$ in $0.1 \mathrm{M} \mathrm{Bu}_{4} \mathrm{NBF}_{4}$ in tetrahydrofuran followed by addition of phosphazene base $\mathrm{P}_{2}$-Et $(\mathrm{P} 2)(15 \mathrm{mM})$ and titration of isopropanol (ipr) at $100 \mathrm{mV} / \mathrm{s}$. (b) [Ipr] dependence on the peak current at $-0.74 \mathrm{~V} \mathrm{v}$. $\mathrm{Fc}^{0 /+}$. 

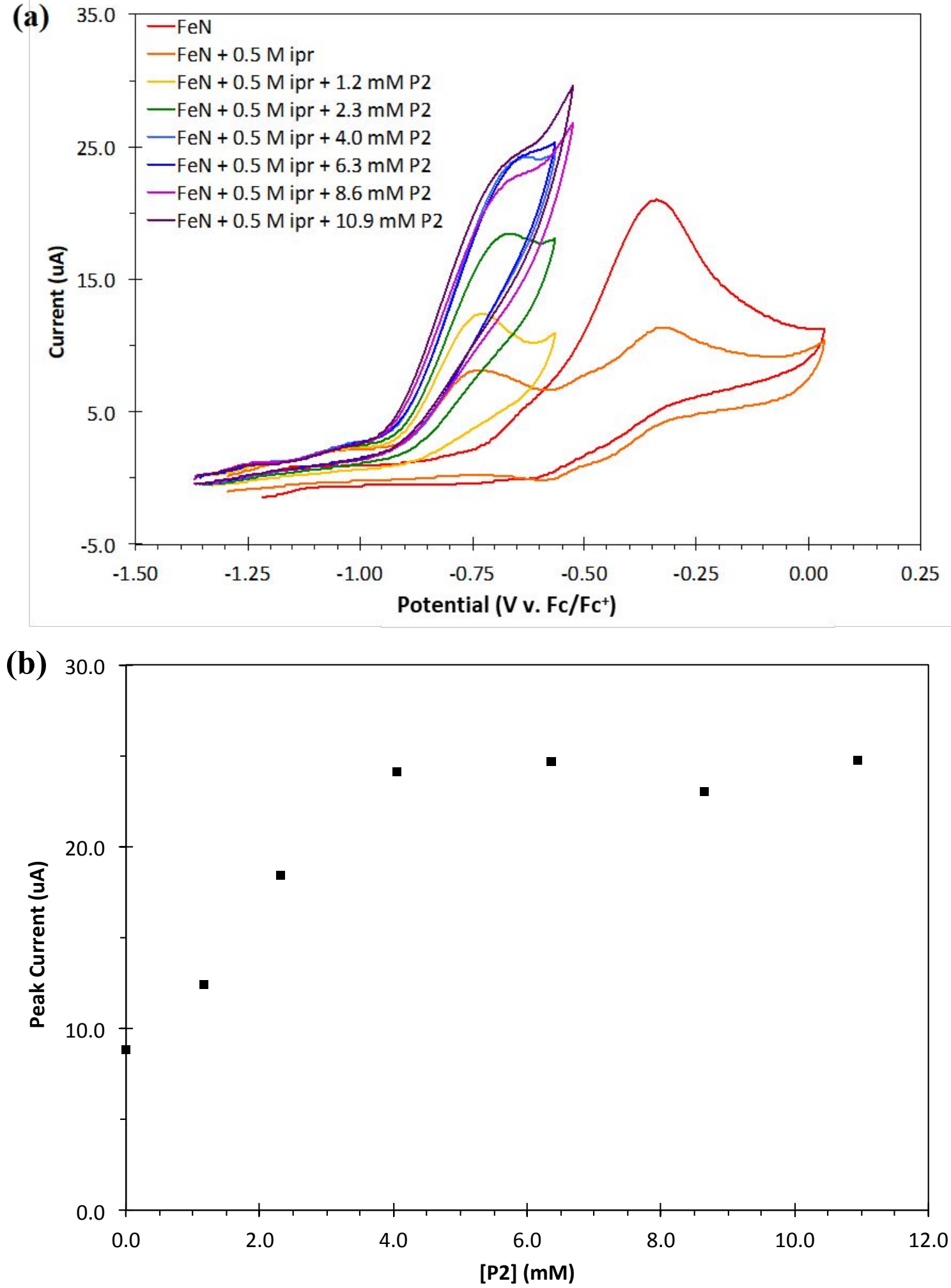
Figure S14. (a) Cyclic voltammograms of FeN $1(1 \mathrm{mM})$ in $0.1 \mathrm{M} \mathrm{Bu}_{4} \mathrm{NBF}_{4}$ in tetrahydrofuran followed by addition of isopropanol $(0.5 \mathrm{M})$ and titration of phosphazene base $\mathrm{P}_{2}-\mathrm{Et}(\mathrm{P} 2)$ at 100 $\mathrm{mV} / \mathrm{s}$. (b) [P2] dependence on the peak current at $-0.74 \mathrm{~V} \mathrm{v}$. $\mathrm{Fc}^{0 /+}$.

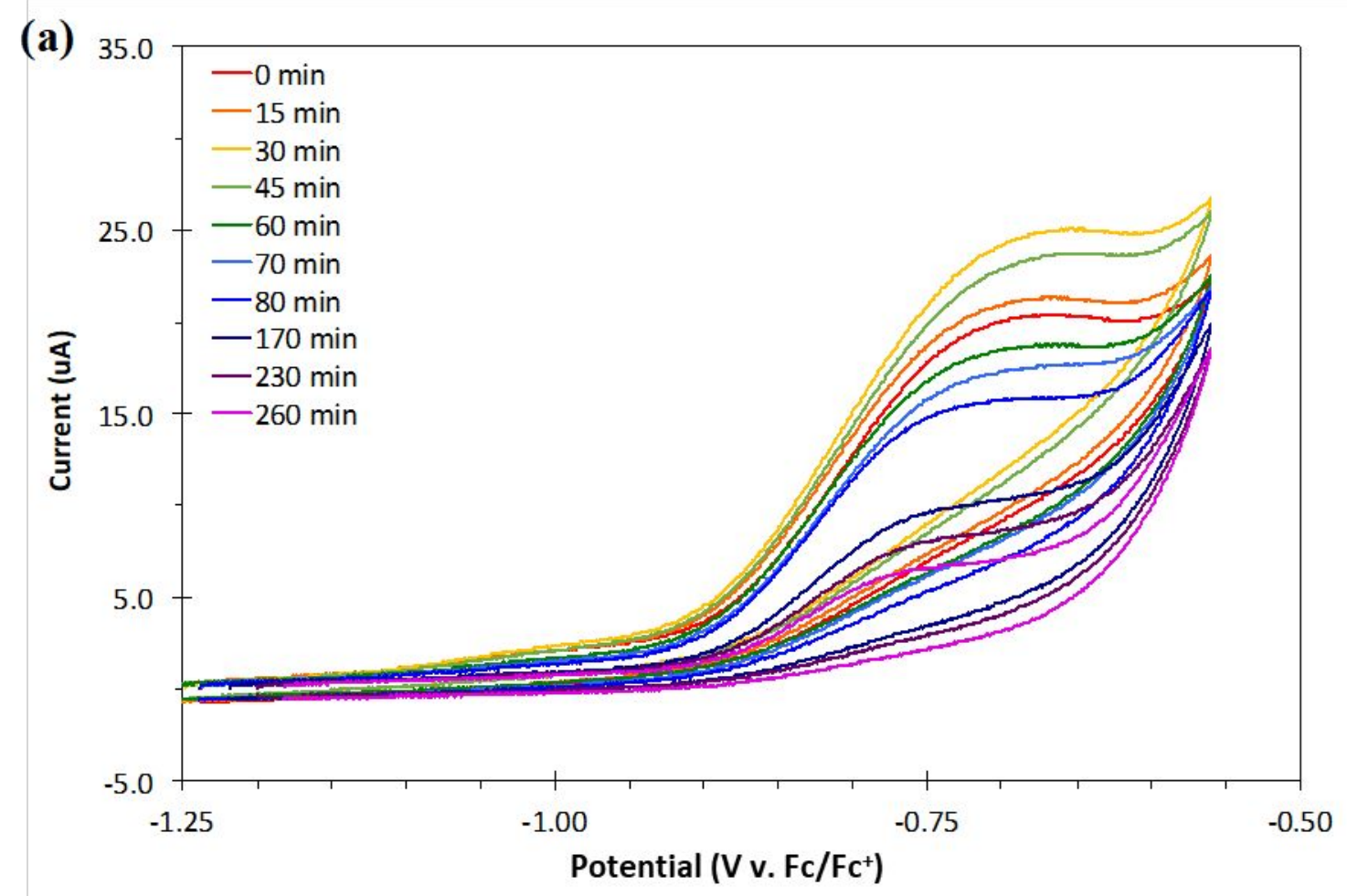

(b)

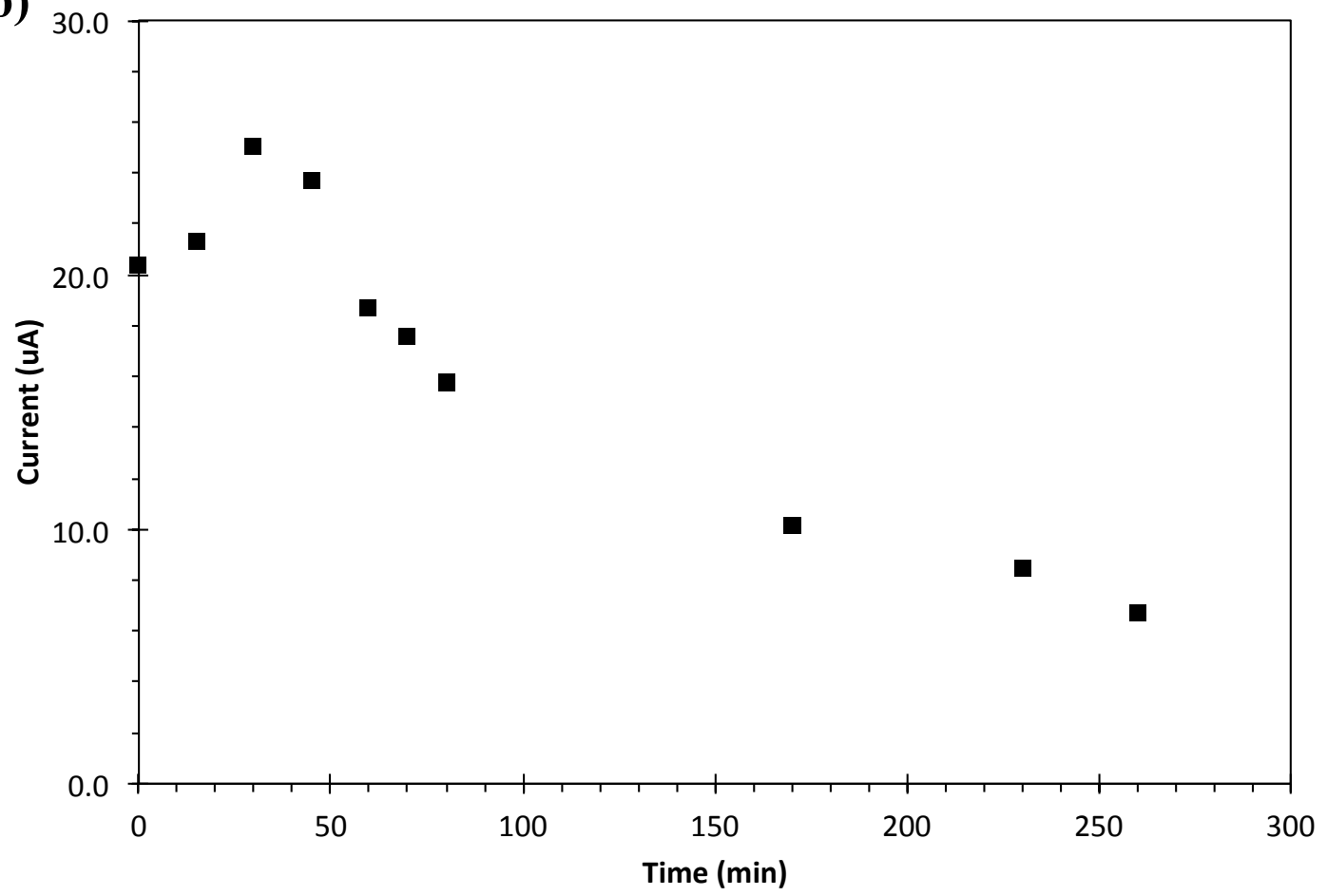


Figure S15. (a) Cyclic voltammograms of $\mathrm{FeN} 1(1 \mathrm{mM})$ in $0.2 \mathrm{M} \mathrm{Bu}_{4} \mathrm{NBF}_{4}$ in $1: 1$ tetrahydrofuran:orthodifluorobenzene with isopropanol $(0.3 \mathrm{M}) \mathrm{P} 2(0.04 \mathrm{M})$ at $100 \mathrm{mV} / \mathrm{s}$. (b) Time dependence on the peak current at $-0.74 \mathrm{~V} v$. $\mathrm{Fc}^{0 /+}$.

\section{Chemical studies}

Dehydrogenation of isopropanol to acetone by FeN 1

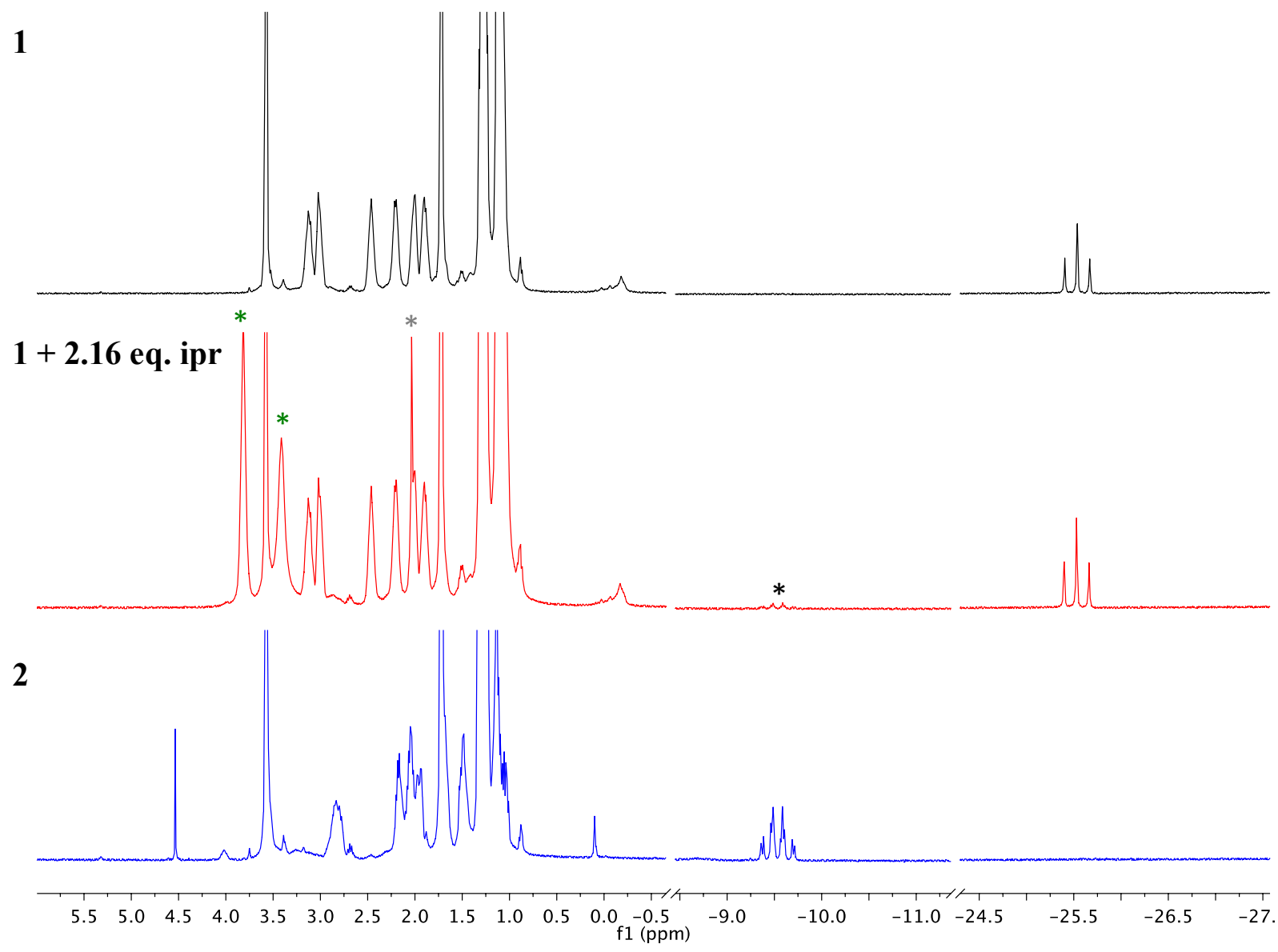

Figure S16. ${ }^{1} \mathrm{H}$ NMR spectra in tetrahydrofuran- $d_{8}$ of the FeN 1 (top spectrum, black), the reaction mixtrue from the addition of 2.16 eq. isopropanol to FeN 1 (middle spectrum, red), and an independetly prepared sample of the $\mathrm{Fe}(\mathrm{H})(\mathrm{NH})$ 2. Isopropanol marked by green asterik, acetone marked by gray asterik, and discernable $\mathrm{Fe}(\mathrm{H})(\mathrm{NH}) 2$ protons marked by black asterik. 
Oxidation of $\mathrm{Fe}(\mathrm{H})(\mathrm{NH}) \mathbf{2}$ in the absence of potassium tert-butoxide (KOtBu). $\mathrm{Fe}(\mathrm{H})(\mathrm{NH}) 2$ was prepared by dissolving FeN 1 in $0.5 \mathrm{~mL}$ dried and degassed tetrahydrofuran- $\mathrm{d}_{8}$ in a J-Young tube in an inert atmosphere glovebox. The solution was degassed via three freezepump-thaw cycles and then exposed to $1 \mathrm{~atm}$ dihydrogen on a Schlenk line. An internal standard ( $2 \mu \mathrm{L}$ of benzene) was added to the solution in an inert atmosphere glovebox, which enabled $\mathrm{Fe}(\mathrm{H})(\mathrm{NH}) 2$ to be quantified by ${ }^{1} \mathrm{H}$ NMR spectroscopy. The solution contained $6.7 \mu \mathrm{mol}$ of the trans $\mathrm{Fe}(\mathrm{H})(\mathrm{NH}) 2.3 \mathrm{mg}(7.2 \mu \mathrm{mol})$ of decamethylferrocenium tetrafluoroborate $\left(\left[\mathrm{Cp}_{2}{ }_{2} \mathrm{Fe}\right]\left[\mathrm{BF}_{4}\right]\right)$ was added to the J-Young containing $\mathrm{Fe}(\mathrm{H})(\mathrm{NH}) 2$. Both ${ }^{1} \mathrm{H}$ and ${ }^{31} \mathrm{P}$ NMR spectra were immediately recorded after the addition of oxidant.

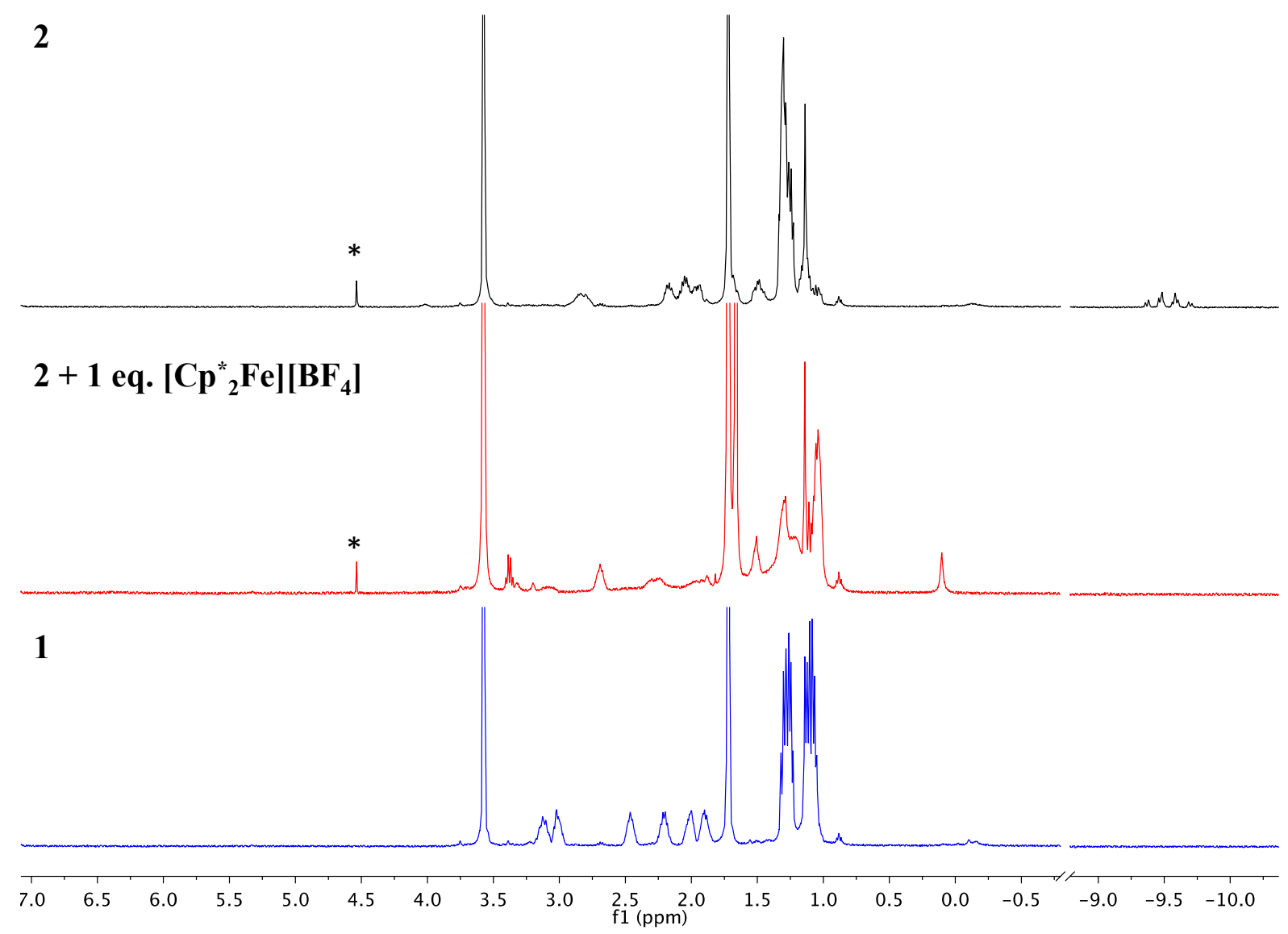

Figure S17. ${ }^{1} \mathrm{H}$ NMR spectra in tetrahydrofuran- $d_{8}$ of $\mathrm{Fe}(\mathrm{H})(\mathrm{NH}) 2$ (top spectrum, black), the reaction mixtrue from the addition of 1 eq. decamethylferrocenium tetrafluoroborate $\left(\left[\mathrm{Cp}_{2}{ }_{2} \mathrm{Fe}\right]\left[\mathrm{BF}_{4}\right]\right)$ (middle spectrum, red), and an independetly prepared sample of FeN $\mathbf{1}$ (bottom spectrum, blue). Dihydrogen is marked by black asterik. 


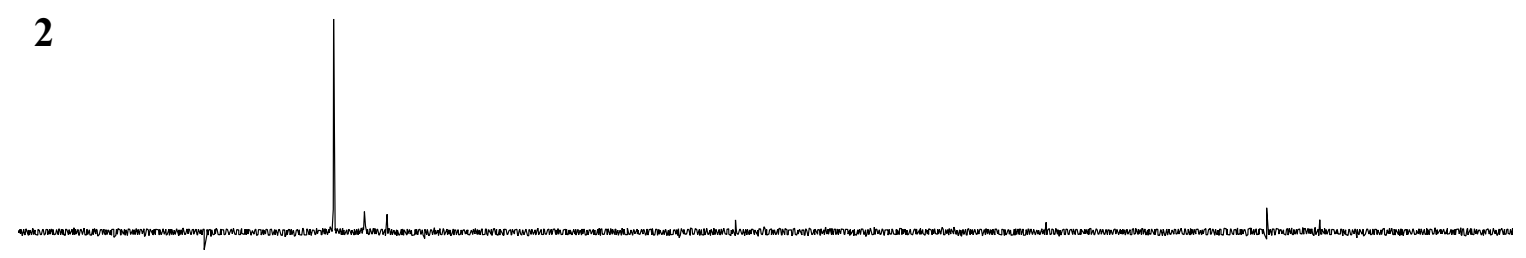

\section{$2+1$ eq. $\left[\mathrm{Cp}_{2}{ }_{2} \mathrm{Fe}\right]\left[\mathrm{BF}_{4}\right]$}

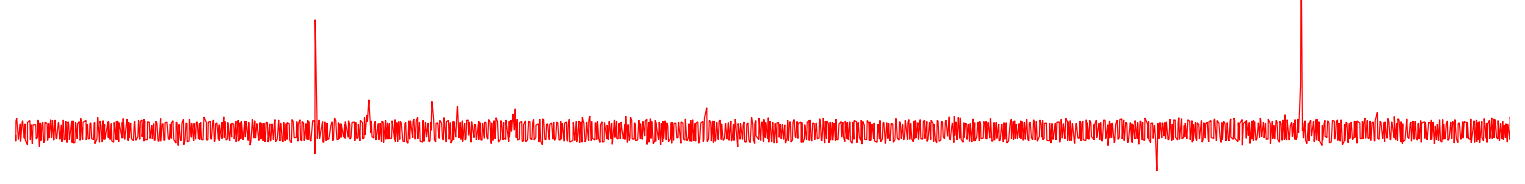
iprPNP ligand, $10 \% \mathrm{w} / \mathrm{v}$ in THF

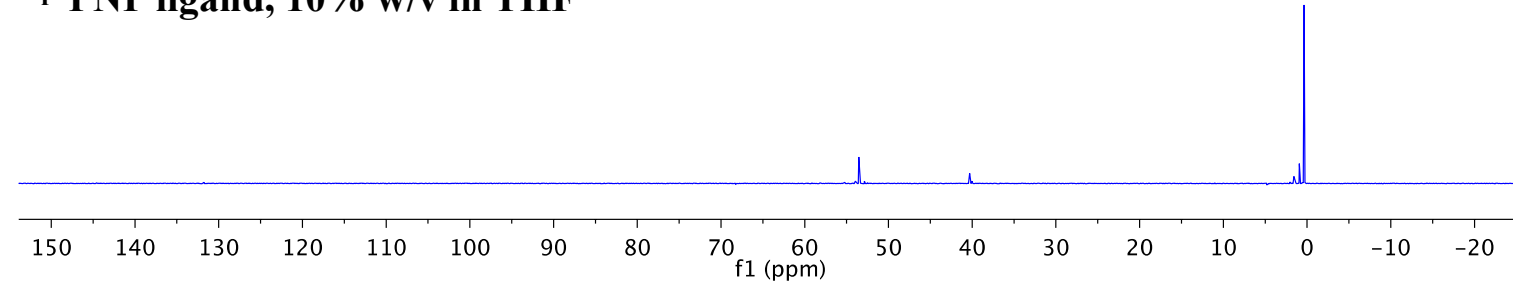

Figure S18. ${ }^{31} \mathrm{P}$ NMR spectra in tetrahydrofuran- $d_{8}$ of $\mathrm{Fe}(\mathrm{H})(\mathrm{NH}) 2$ (top spectrum, black), the reaction mixtrue from the addition of 1 eq. decamethylferrocenium tetrafluoroborate $\left(\left[\mathrm{Cp}_{2}{ }_{2} \mathrm{Fe}\right]\left[\mathrm{BF}_{4}\right]\right.$ ) (middle spectrum, red), and commerically available $10 \%$ by weight solution of the bis[2-(diisopropylphosphino)ethyl]amine (iprPNP) ligand in tetrahydrofuran. 
Oxidation of $\mathrm{Fe}(\mathrm{H})(\mathrm{NH}) \mathbf{2}$ in the presence of potassium tert-butoxide (KOtBu). $\mathrm{Fe}(\mathrm{H})(\mathrm{NH}) 2$ was prepared by dissolving $\mathrm{FeN} 1$ in $0.5 \mathrm{~mL}$ dried and degassed tetrahydrofuran- $\mathrm{d}_{8}$ in a J-Young tube in an inert atmosphere glovebox. The solution was degassed via three freezepump-thaw cycles and then exposed to $1 \mathrm{~atm}$ dihydrogen on a Schlenk line. An internal standard ( $2 \mu \mathrm{L}$ of benzene) was added to the solution in an inert atmosphere glovebox, which enabled $\mathrm{Fe}(\mathrm{H})(\mathrm{NH}) 2$ to be quantified by ${ }^{1} \mathrm{H}$ NMR spectroscopy. The solution contained $11.6 \mu \mathrm{mol}$ of the trans $\mathrm{Fe}(\mathrm{H})(\mathrm{NH}) 2.15 \mathrm{mg}(134 \mu \mathrm{mol})$ of potassium $t$-butoxide $(\mathrm{KOtBu})$ and $9 \mathrm{mg}(22 \mu \mathrm{mol})$ of decamethylferrocenium tetrafluoroborate $\left(\left[\mathrm{Cp}_{2}{ }_{2} \mathrm{Fe}\right]\left[\mathrm{BF}_{4}\right]\right)$ were sequentially added to the $\mathrm{J}$ Young containing $\mathrm{Fe}(\mathrm{H})(\mathrm{NH}) 2$. Both ${ }^{1} \mathrm{H}$ and ${ }^{31} \mathrm{P}$ NMR spectra were immediately recorded after the addition of base and oxidant.

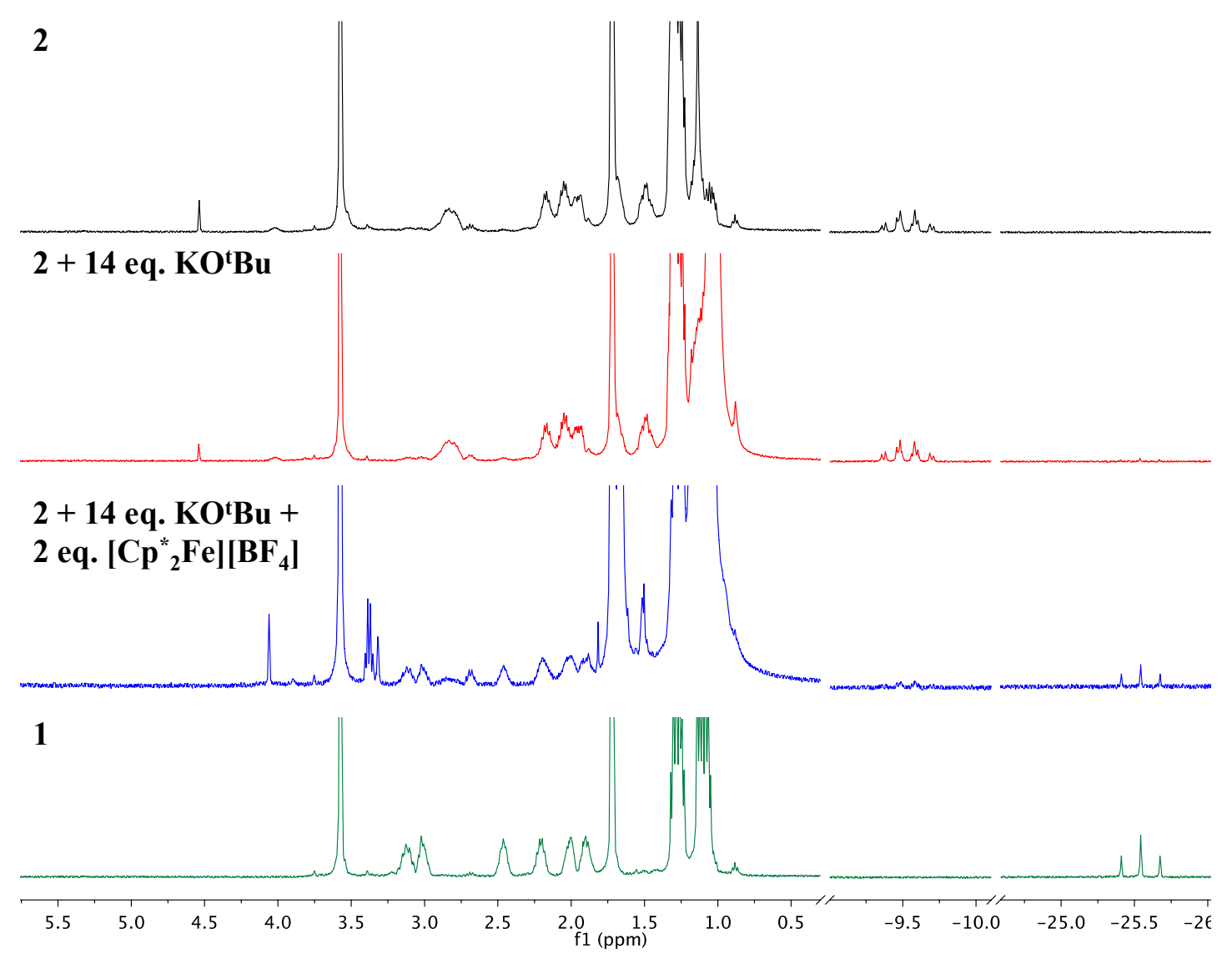

Figure S19. ${ }^{1} \mathrm{H}$ NMR spectra in tetrahydrofuran- $d_{8}$ of the $\mathrm{Fe}(\mathrm{H})(\mathrm{NH}) 2$ (top spectrum, black), upon addition of 14 eq. potassium tert-butoxide ( $\mathrm{KOtBu}$ ) (middle spectrum, red), upon subseqeunt addition of 2 eq. decamethylferrocenium tetrafluoroborate $\left(\left[\mathrm{Cp}_{2}{ }_{2} \mathrm{Fe}\right]\left[\mathrm{BF}_{4}\right]\right)$ (middle spectrum, blue), and an independetly prepared sample of FeN 1 (bottom spectrum, green). 


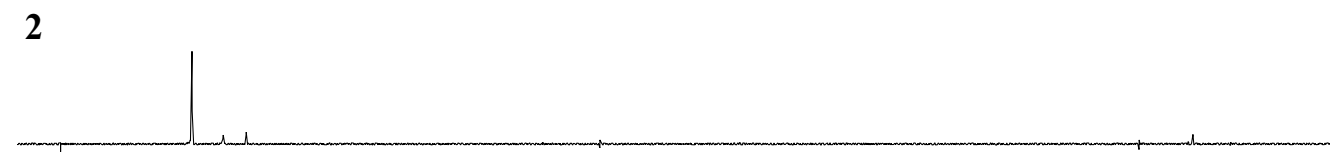

\section{$2+14$ eq. KO'Bu}

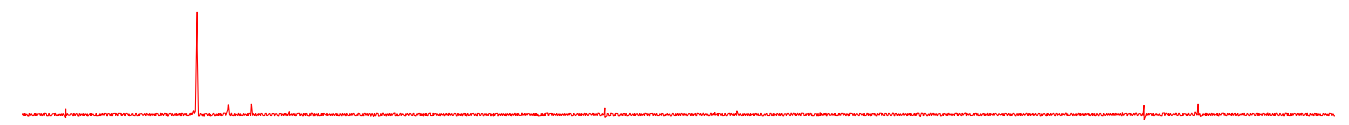

\section{$2+14$ eq. $\mathrm{KO}^{\mathrm{t} B u}+2 \mathrm{eq} \cdot\left[\mathrm{Cp}_{2}{ }_{2} \mathrm{Fe}\right]\left[\mathrm{BF}_{4}\right]$}

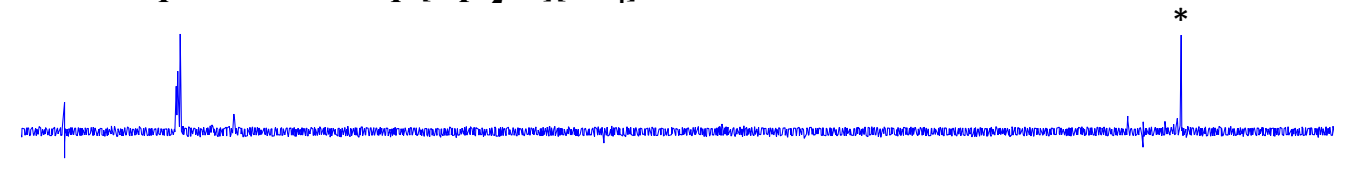

1

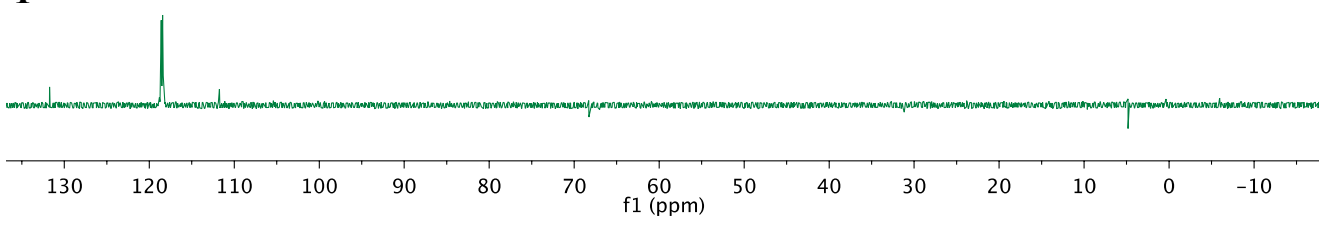

Figure S20. ${ }^{31} \mathrm{P}$ NMR spectra in tetrahydrofuran- $d_{8}$ of $\mathrm{Fe}(\mathrm{H})(\mathrm{NH}) 2$ (top spectrum, black), upon addition of 14 eq. potassium tert-butoxide (KOtBu) (middle spectrum, red), upon subseqeunt addition of 2 eq. decamethylferrocenium tetrafluoroborate $\left(\left[\mathrm{Cp}_{2}{ }_{2} \mathrm{Fe}\right][\mathrm{BF} 4]\right.$ ) (middle spectrum, blue), and an independetly prepared sample of FeN 1 (bottom spectrum, green). Free ligand is marked by a black asterik.

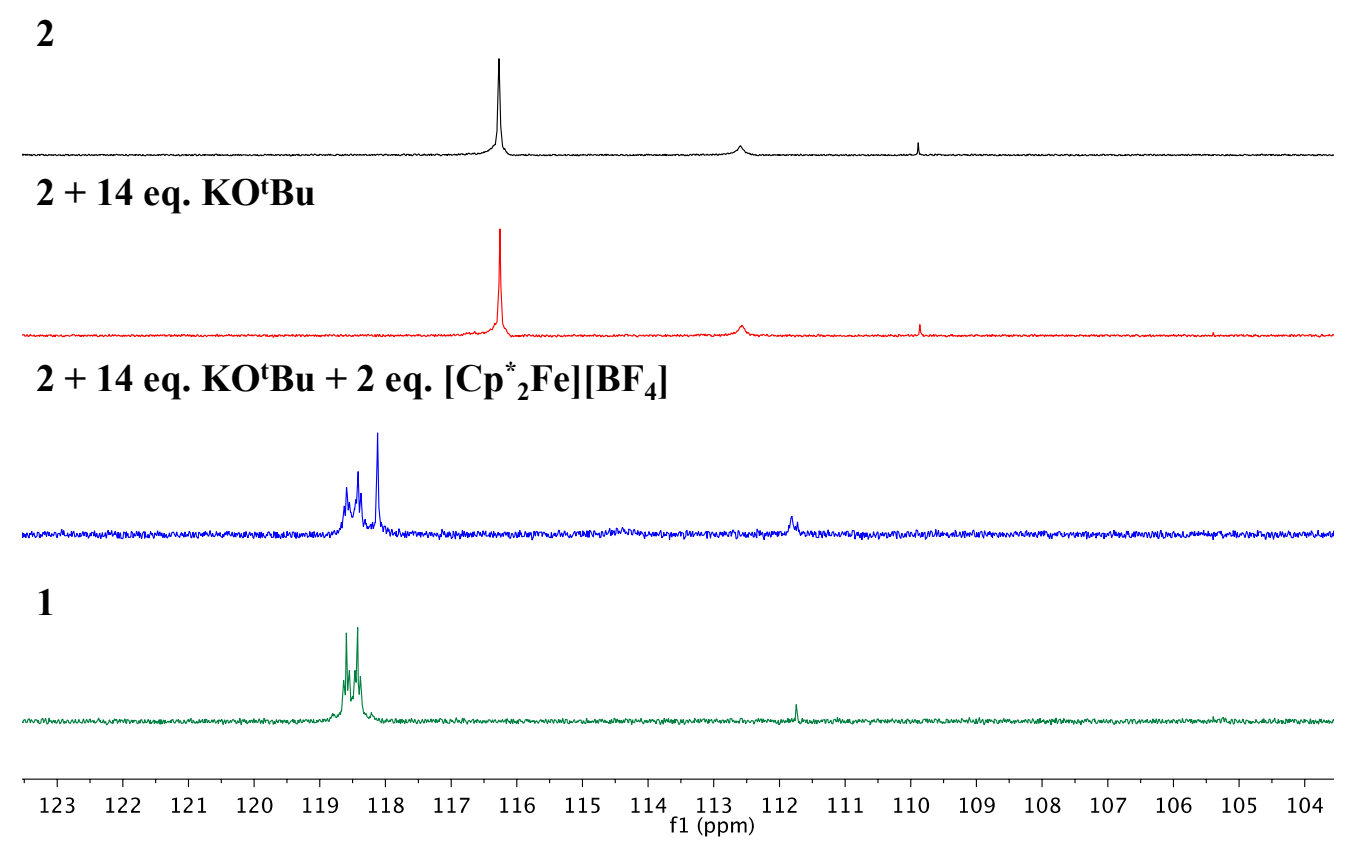

Figure S21. ${ }^{31} \mathrm{P}$ NMR spectra in tetrahydrofuran- $d_{8}$ of $\mathrm{Fe}(\mathrm{H})(\mathrm{NH}) 2$ (top spectrum, black), upon addition of 14 eq. potassium tert-butoxide (KOtBu) (middle spectrum, red), upon subseqeunt addition of 2 eq. decamethylferrocenium tetrafluoroborate $\left(\left[\mathrm{Cp}_{2}{ }_{2} \mathrm{Fe}\right]\left[\mathrm{BF}_{4}\right]\right)$ (middle spectrum, blue), and an independetly prepared sample of the FeN 1 (bottom spectrum, green). 


\section{Controlled Potential Electrolysis Studies}

Exhaustive Oxidation of $\mathrm{Fe}(\mathrm{H})(\mathrm{NH}) 2$ in the absence of phosphazene base P2 (P $\mathrm{P}_{2}$ Et, Et$N=P_{2}(d m a)_{5} . \mathrm{Fe}(\mathrm{H})(\mathrm{NH}) 2$ was prepared by dissolving FeN 1 in $0.5 \mathrm{~mL}$ dried and degassed tetrahydrofuran- $\mathrm{d}_{8}$ in a $\mathrm{J}$-Young tube in an inert atmosphere glovebox. The solution was degassed via three freeze-pump-thaw cycles and then exposed to 1 atm dihydrogen on a Schlenk line. An internal standard ( $2 \mu \mathrm{L}$ of benzene) was added to the solution in an inert atmosphere glovebox, which enabled $\mathrm{Fe}(\mathrm{H})(\mathrm{NH}) 2$ to be quantified by ${ }^{1} \mathrm{H}$ NMR spectroscopy. The solution contained $7.85 \mu \mathrm{mol}$ of the trans $\mathrm{Fe}(\mathrm{H})(\mathrm{NH}) 2$ and $1.35 \mu \mathrm{mol}$ of the cis amino hydride, yielding 9.20 $\mu \mathrm{mol}$ total amino hydride. The electrolysis cell containing the carbon cloth working electrode $(1.0 \times 4.0 \mathrm{~cm})$ and $\mathrm{Ag} / \mathrm{AgNO}_{3}$ reference electrode was charged with this amino hydride solution in $0.2 \mathrm{M} \mathrm{Bu}_{4} \mathrm{NPF}_{6}$ in 1:1 tetrahydrofuran:orthodifluorobenzene. The total concentration of amino hydride in the electrolysis solution was $0.54 \mathrm{mM}$. The auxiliary electrode compartment was filled with electrolyte solution at the same concentration. Controlled potential electrolysis was performed at $-0.65 \mathrm{~V}$ versus $\mathrm{Fc}^{0 /+}$. The charge passed during the electrolysis was $0.80 \mathrm{C}$, determined by integration of the current versus time curve (Figure S21). This value is in good agreement with $0.887 \mathrm{C}$, the theoretical total charge passed for the one-electron oxidation of total amino hydride calculated according to:

$$
Q=n F N_{2}
$$

where $n=$ number of electrons, $F=$ Faraday's constant, and $N_{2}=$ moles of 2. 


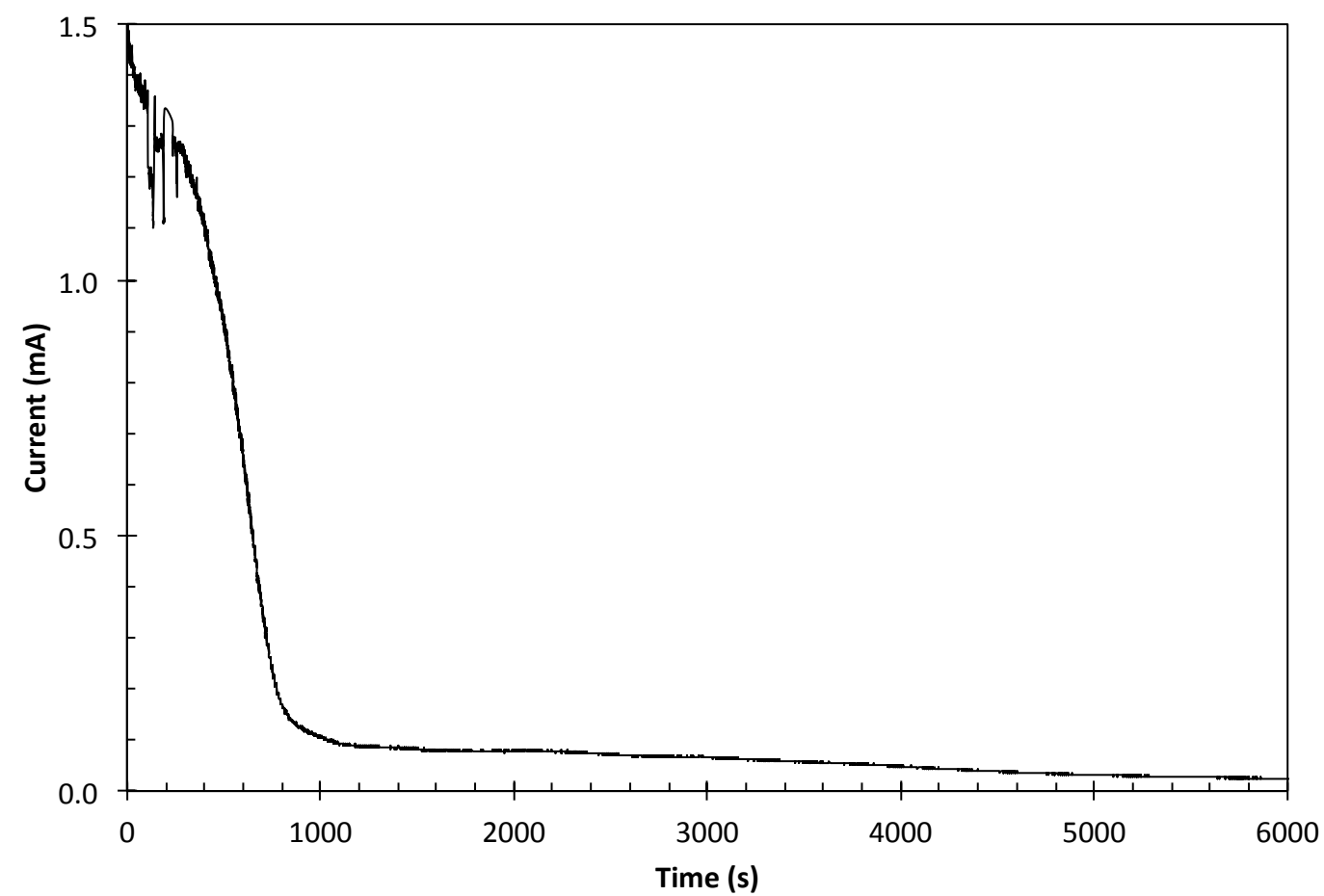

Figure S22. Controlled-potential electrolysis of $\mathrm{Fe}(\mathrm{H})(\mathrm{NH}) 2(0.54 \mathrm{mM})$ in $0.2 \mathrm{M} \mathrm{Bu}_{4} \mathrm{NBF}_{4}$ in $1: 1$ tetrahydrofuran:orthodifluorobenzene at $-0.65 \mathrm{~V}$ versus $\mathrm{Fc}^{0 /+}$. A $4.0 \times 1.0 \mathrm{~cm}$ carbon cloth working electrode was used for CPE experiments. 
Exhaustive Oxidation of 2 in the presence of phosphazene base P2 $\left(P_{2}-E t\right.$, Et$\left.N=P_{2}(d m a)_{5}\right)$. $\mathrm{Fe}(\mathrm{H})(\mathrm{NH}) 2$ was prepared by dissolving FeN 1 in $0.5 \mathrm{~mL}$ dried and degassed tetrahydrofuran- $\mathrm{d}_{8}$ in a J-Young tube in an inert atmosphere glovebox. The solution was degassed via three freeze-pump-thaw cycles and then exposed to $1 \mathrm{~atm}$ dihydrogen on a Schlenk line. An internal standard ( $2 \mu \mathrm{L}$ of benzene) was added to the solution in an inert atmosphere glovebox, which enabled $\mathrm{Fe}(\mathrm{H})(\mathrm{NH}) 2$ to be quantified by ${ }^{1} \mathrm{H}$ NMR spectroscopy. The solution contained $3.7 \mu \mathrm{mol}$ of the trans $\mathrm{Fe}(\mathrm{H})(\mathrm{NH}) 2$ and $0.9 \mu \mathrm{mol}$ of the cis amino hydride, yielding 4.6 $\mu$ mol total amino hydride. The electrolysis cell containing the carbon cloth working electrode $(4.0 \times 1.0 \mathrm{~cm})$ and $\mathrm{Ag} / \mathrm{AgNO}_{3}$ reference electrode was charged with this amino hydride solution in $\quad 0.2 \mathrm{M} \quad \mathrm{Bu}_{4} \mathrm{NBF}_{4}$ with $10 \mathrm{mM}$ phosphazene base $\mathrm{P}_{2}$-Et in 1:1 tetrahydrofuran:orthodifluorobenzene. The total concentration of amino hydride in the electrolysis solution was $0.23 \mathrm{mM}$. The auxiliary electrode compartment was filled with electrolyte solution at the same concentration. Controlled potential electrolysis was performed at $-0.65 \mathrm{~V}$ versus $\mathrm{Fc}^{0 /+}$. The charge passed during the electrolysis was $0.82 \mathrm{C}$, determined by integration of the current versus time curve (Figure S22). This value is in good agreement with $0.89 \mathrm{C}$, the theoretical total charge passed for the two-electron oxidation of total amino hydride calculated according to:

$$
Q=n F N_{2}
$$

where $n=$ number of electrons, $F=$ Faraday's constant, and $N_{2}=$ moles of $\mathbf{2}$. 


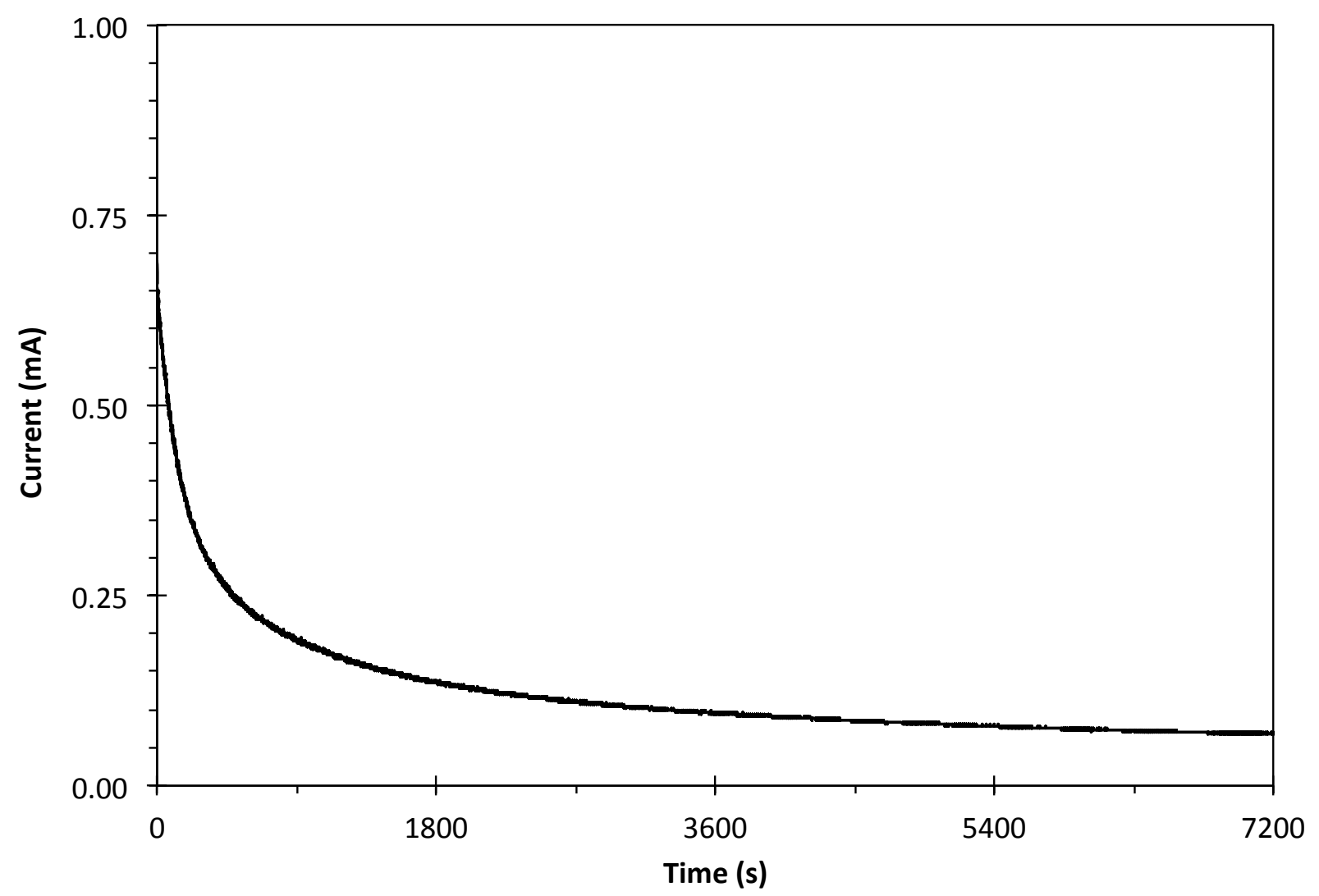

Figure S23. Controlled-potential electrolysis of $\mathrm{Fe}(\mathrm{H})(\mathrm{NH}) 2(0.23 \mathrm{mM})$ in $0.2 \mathrm{M} \mathrm{Bu}_{4} \mathrm{NBF}_{4}$ in 1:1 tetrahydrofuran:orthodifluorobenzene with phosphazene base $\mathrm{P}_{2}$-Et $(10 \mathrm{mM})$ at $-0.65 \mathrm{~V}$ versus $\mathrm{Fc}^{0 /+}$. A 4.0 x $1.0 \mathrm{~cm}$ carbon cloth working electrode was used for $\mathrm{CPE}$ experiments. 
Electrocatalytic Activity with FeN 1. The electrolysis cell containing the carbon cloth working electrode $(4.0 \times 1.0 \mathrm{~cm})$ and $\mathrm{Ag} / \mathrm{AgNO}_{3}$ reference electrode was charged with $15.5 \mathrm{~mL}$ of $1.5 \mathrm{mM} \mathrm{FeN} 1$ in $0.2 \mathrm{M} \mathrm{Bu}_{4} \mathrm{NBF}_{4}$ with $0.3 \mathrm{M}$ isopropanol and $0.04 \mathrm{M}$ phosphazene base $\mathrm{P}_{2}$-Et in 1:1 tetrahydrofuran:orthodifluorobenzene. The auxiliary electrode compartment was filled with electrolyte solution at the same concentration. Controlled potential electrolysis was performed at $-0.80 \mathrm{~V}$ versus $\mathrm{Fc}^{0 /+}$. The charge passed during the electrolysis was $6.76 \mathrm{C}$, determined by integration of the current versus time curve (Figure S22). The theoretical acetone production for this charge $\mathrm{Q}$ is $0.035 \mathrm{mmol}$ using the following equation:

$$
Q=n F N_{\text {acetone }}
$$

where $n=$ number of electrons, $F=$ Faraday's constant, and $N_{\text {acetone }}=$ moles acetone.

Acetone was quantified using ${ }^{1} \mathrm{H}$ NMR spectroscopy. NMR samples were prepared by mixing $500 \mu \mathrm{L}$ of the electrolysis solution with $400 \mu \mathrm{L} \mathrm{C}_{6} \mathrm{D}_{6}$, and $100 \mu \mathrm{L}$ of $0.1 \mathrm{M} \mathrm{1,3,5-}$ trimethoxybenzene in $\mathrm{C}_{6} \mathrm{D}_{6}$ as an internal standard. Resonances corresponding to the electrolyte $\left(\mathrm{Bu}_{4} \mathrm{NBF}_{4}\right.$ ), solvent (tetrahydrofuran, orthodifluorobenzene), substrate (isopropanol), and base (phosphazene base $\mathrm{P}_{2}$-Et) were suppressed. The integration of the acetone singlet resonance at $1.7 \mathrm{ppm}$ was compared to the integration of the 1,3,5-trimethoxybenzene sinlget resonance at 5.5 $\mathrm{ppm}$. To determine the amount of acetone at produced in the absence of an applied potential, a 1 $\mathrm{mL}$ aliquot of the electrolysis solution was set aside before starting the electrolysis. In the absence of an applied potential, slightly less than one equivalent of acetone was produced $(0.017$ mmol). During the electrolysis, $0.039 \mathrm{mmol}$ of acetone was produced, corresponding to a turnover number of 1.9. Given that two equivalents of base are required to convert one equivalent of isopropanol to acetone, only $20 \mathrm{mM}$ of acetone can be produced. Roughly $2.5 \mathrm{mM}$ of acetone were produced, yielding a conversion of roughly $12.5 \%$. The Faradaic efficiency for acetone production is $102 \pm 15 \%$. 


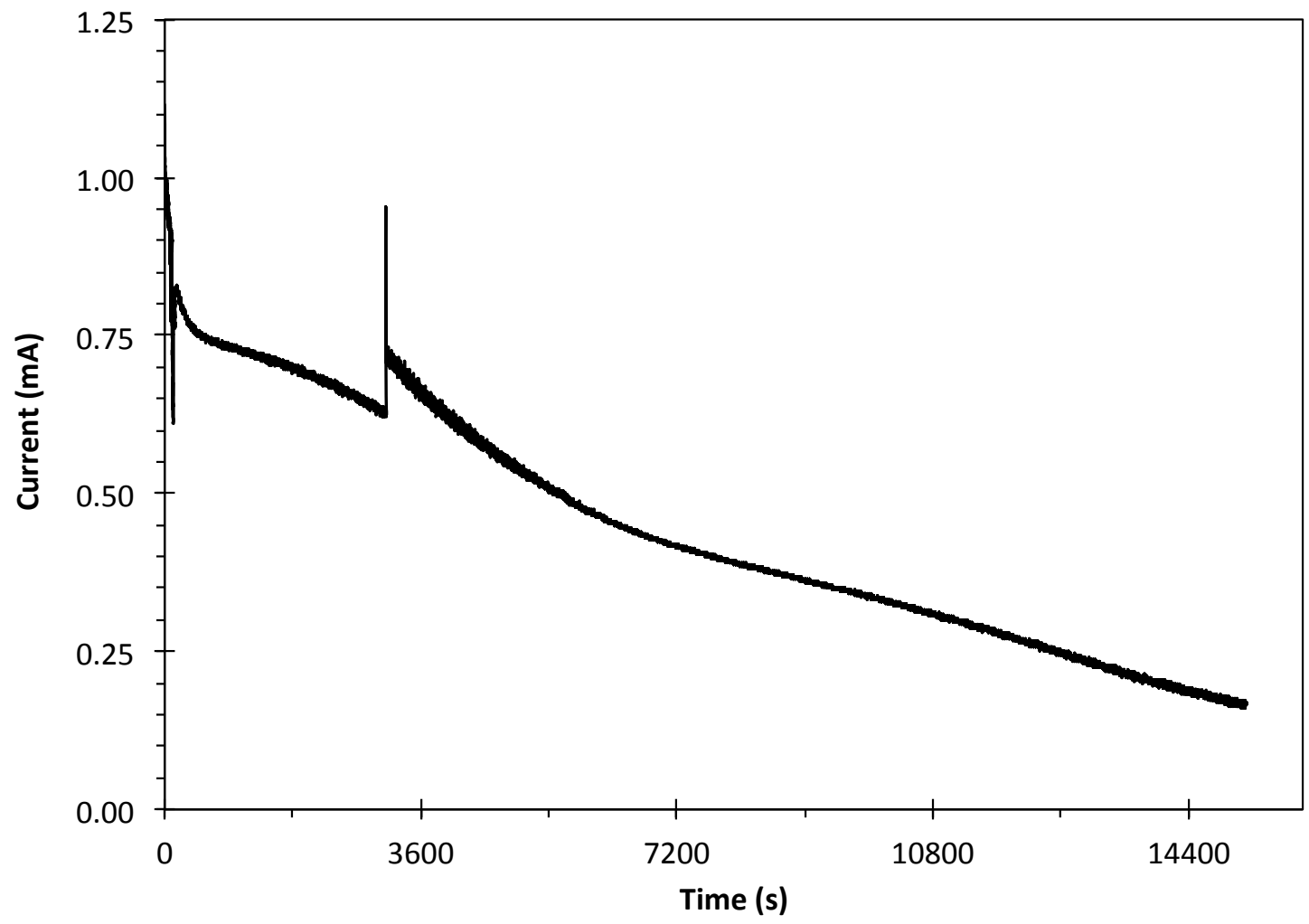

Figure S24. Controlled-potential electrolysis of FeN $1(1.5 \mathrm{mM})$ with $0.3 \mathrm{M}$ isopropanol and $0.04 \mathrm{M}$ phosphazene base $\mathrm{P}_{2}$-Et in $0.2 \mathrm{M} \mathrm{Bu}_{4} \mathrm{NBF}_{4}$ in $1: 1$ tetrahydrofuran:orthodifluorobenzene at $-0.8 \mathrm{~V}$ versus $\mathrm{Fc}^{0 /+}$. A $4.0 \times 1.0 \mathrm{~cm}$ carbon cloth working electrode was used for $\mathrm{CPE}$ experiments. 

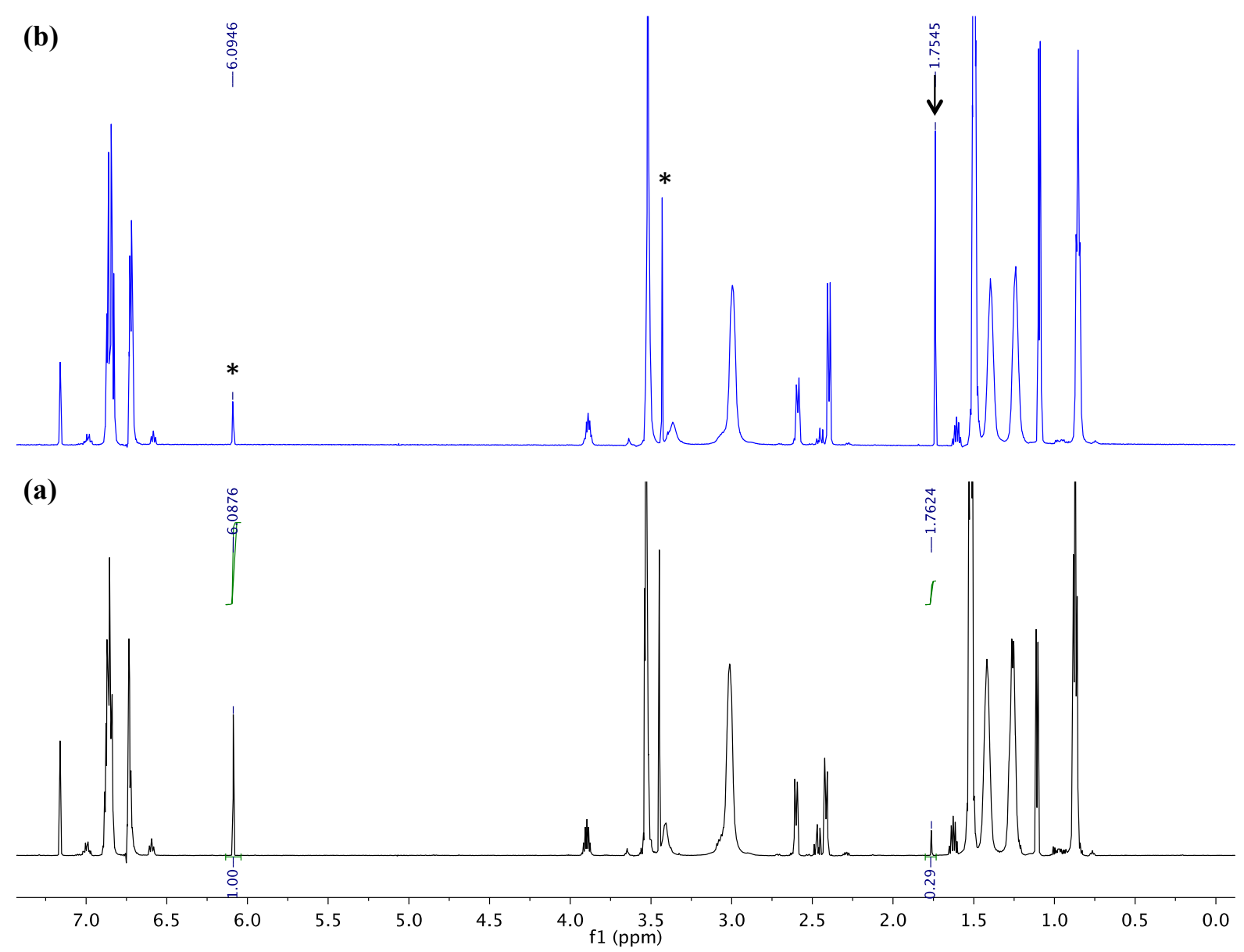

Figure S25. Representative solvent suppresed ${ }^{1} \mathrm{H}$ NMR spectrum of a) the electrolysis solution and $\mathrm{b}$ ) the electrolysis solution after spiking in $2 \mu \mathrm{L}$ acetone. Resonances corresponding to the electrolyte $\left(\mathrm{Bu}_{4} \mathrm{NBF}_{4}\right)$, solvent (tetrahydrofuran, orthodifluorobenzene), substrate (isopropanol), and base (phosphazene base $\mathrm{P}_{2}$-Et) were suppressed. Resonances corresponding to the internal standard 1,3,5-trimethoxybenzene are indicated with an asterisk and the resonance corresponding to acetone is indicated with an arrow. Quantification of acetone was determined by comparing the integration of the acetone singlet at $1.76 \mathrm{ppm}$ to the integration of the 1,3,5trimethoxybenzene sinlget at $6.09 \mathrm{ppm}$. 


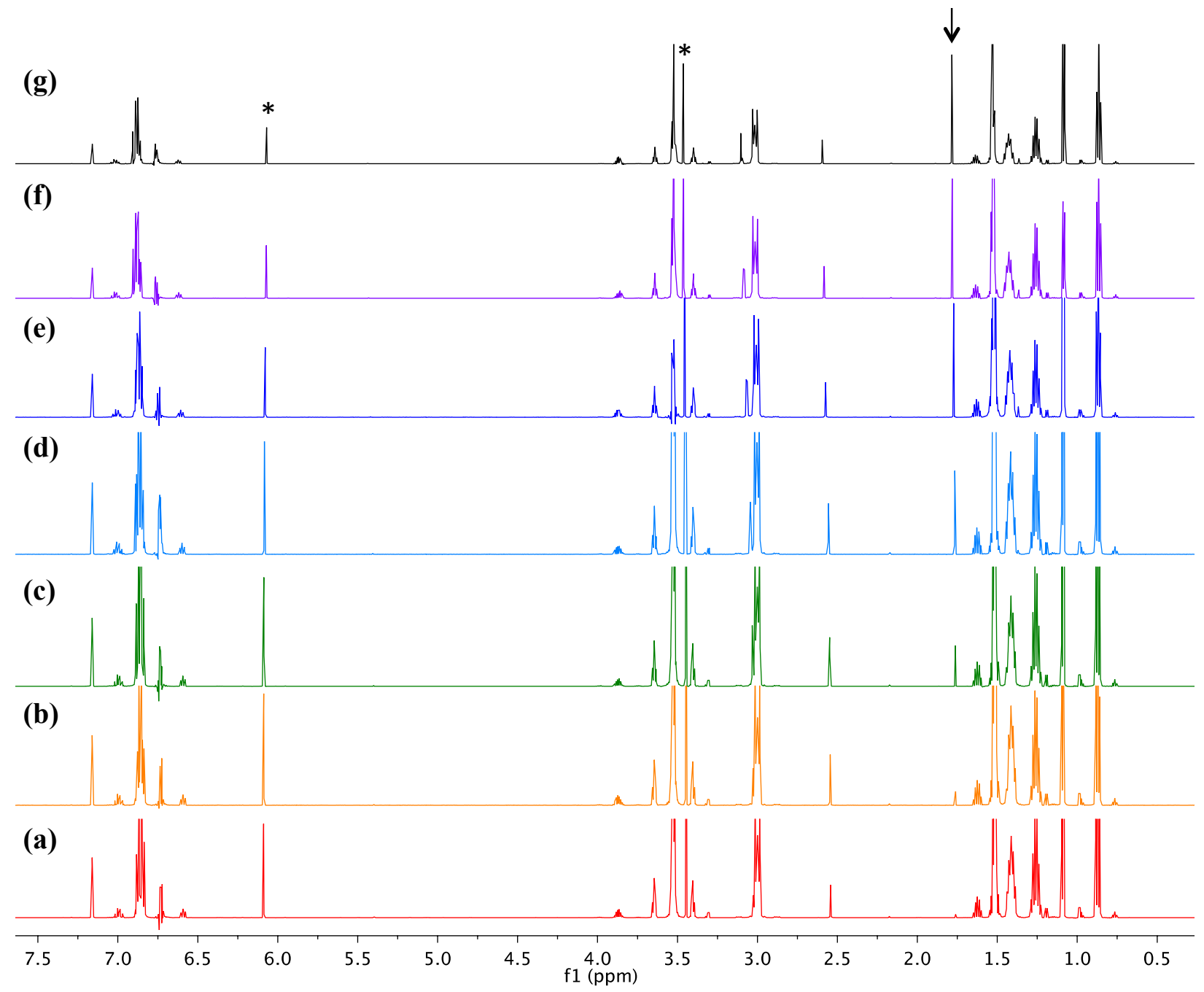

Figure S26. Solvent suppresed ${ }^{1} \mathrm{H}$ NMR spectra of acetone calibration solutions. Calibration solutions contained $0.01 \mathrm{M}$ 1,3,5-trimethoxybenzene and $0.3 \mathrm{M}$ isopropanol in a $1: 1$ tetrahydrofuran:orthodifluorobenzene containing $0.2 \mathrm{M} \mathrm{Bu}_{4} \mathrm{NBF}_{4}$. The concentration of acetone was (a) $0.6 \mathrm{mM}$ (b) $1.2 \mathrm{mM}$ (c) $2.4 \mathrm{mM}$ (d) $4.6 \mathrm{mM}$ (e) $8.8 \mathrm{mM}$ (f) $12.5 \mathrm{mM}$ and (g) $16.0 \mathrm{mM}$. Resonances corresponding to the electrolyte $\left(\mathrm{Bu}_{4} \mathrm{NBF}_{4}\right)$, solvent (tetrahydrofuran, orthodifluorobenzene), substrate (isopropanol), and base (phosphazene base $\mathrm{P}_{2}$-Et) were suppressed. Resonances corresponding to the internal standard 1,3,5-trimethoxybenzene are indicated with an asterisk and the resonance corresponding to acetone is indicated with an arrow. Quantification of acetone was determined by comparing the integration of the acetone singlet at $1.76 \mathrm{ppm}$ to the integration of the 1,3,5-trimethoxybenzene sinlget at $6.09 \mathrm{ppm}$. 


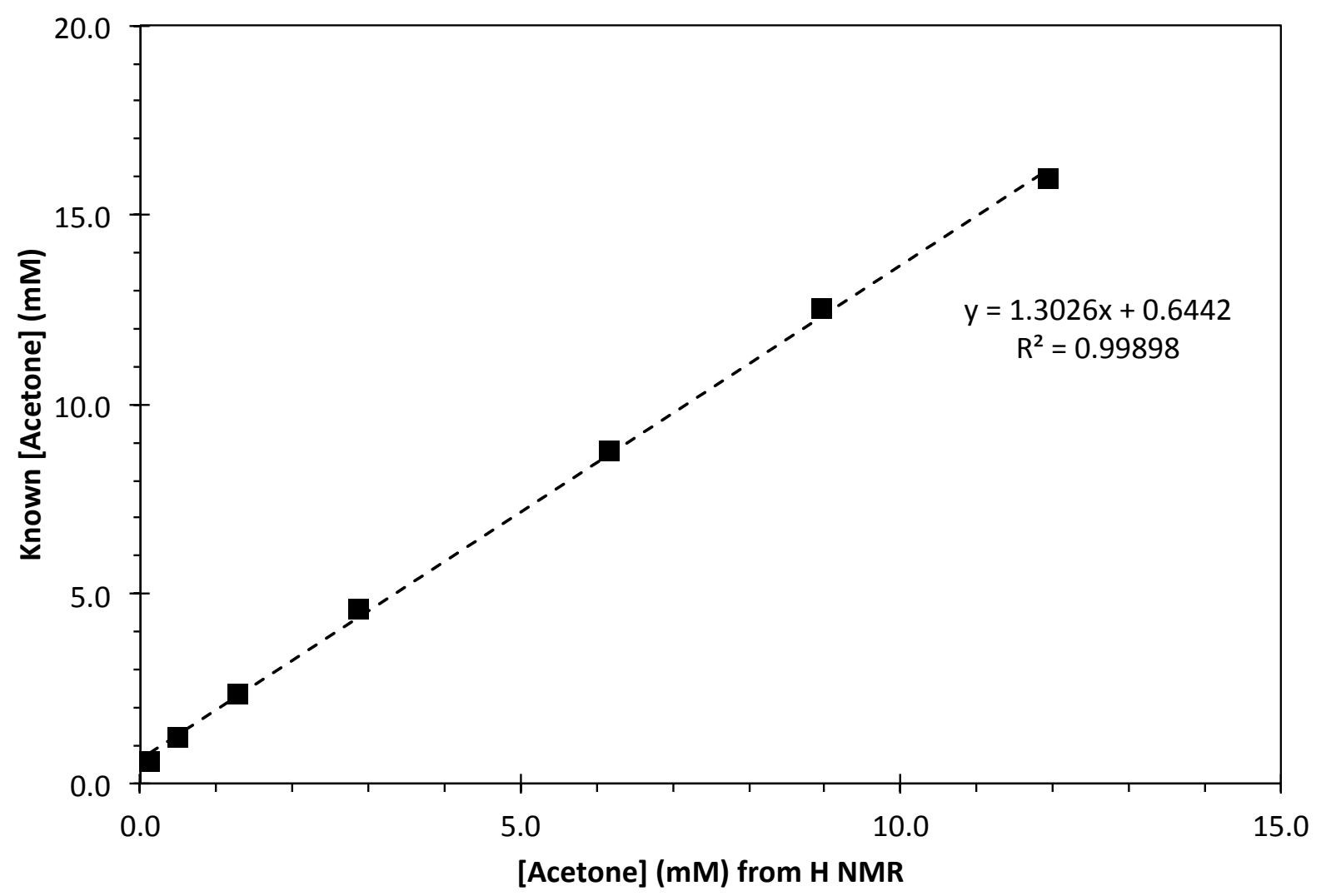

Figure S27. Calibration curve for acetone quantification using solvent supressed ${ }^{1} \mathrm{H}$ NMR techqniue. Quantification of acetone was determined by comparing the integration of the acetone singlet at $1.7 \mathrm{ppm}$ to the integration of the 1,3,5-trimethoxybenzene sinlget at $5.5 \mathrm{ppm}$ from the ${ }^{1} \mathrm{H}$ NMR spectra in Figure S25. 
Electrocatalytic Activity without FeN 1. The electrolysis cell containing the carbon cloth working electrode $(4.0 \times 1.0 \mathrm{~cm})$ and $\mathrm{Ag} / \mathrm{AgNO}_{3}$ reference electrode was charged with $15.5 \mathrm{~mL}$ of $0.2 \mathrm{M} \mathrm{Bu}_{4} \mathrm{NBF}_{4}$ with $0.3 \mathrm{M}$ isopropanol and $0.04 \mathrm{M}$ phosphazene base $\mathrm{P}_{2}$-Et in 1:1 tetrahydrofuran:orthodifluorobenzene. The auxiliary electrode compartment was filled with electrolyte solution at the same concentration. Controlled potential electrolysis was performed at $-0.70 \mathrm{~V}$ versus $\mathrm{Fc}^{0 /+}$. The charge passed during the electrolysis was $0.09 \mathrm{C}$, determined by integration of the current versus time curve (Figure S23). The theoretical acetone production for this charge $\mathrm{Q}$ is $0.0005 \mathrm{mmol}$ using the following equation:

$$
Q=n F N_{\text {acetone }}
$$

where $n=$ number of electrons, $F=$ Faraday's constant, and $N_{\text {acetone }}=$ moles acetone.

Acetone was quantified using ${ }^{1} \mathrm{H}$ NMR spectroscopy. NMR samples were prepared by mixing $500 \mu \mathrm{L}$ of the electrolysis solution with $400 \mu \mathrm{L} \mathrm{C}_{6} \mathrm{D}_{6}$ and $100 \mu \mathrm{L}$ of $0.1 \mathrm{M} \mathrm{1,3,5-}$ trimethoxybenzene in $\mathrm{C}_{6} \mathrm{D}_{6}$ as an internal standard. Resonances corresponding to the electrolyte $\left(\mathrm{Bu}_{4} \mathrm{NBF}_{4}\right)$, solvent (tetrahydrofuran, orthodifluorobenzene), and base (phosphazene base $\mathrm{P}_{2}$-Et) were suppressed. Both before and after the electrolysis, no acetone was detected via ${ }^{1} \mathrm{H}$ NMR. 


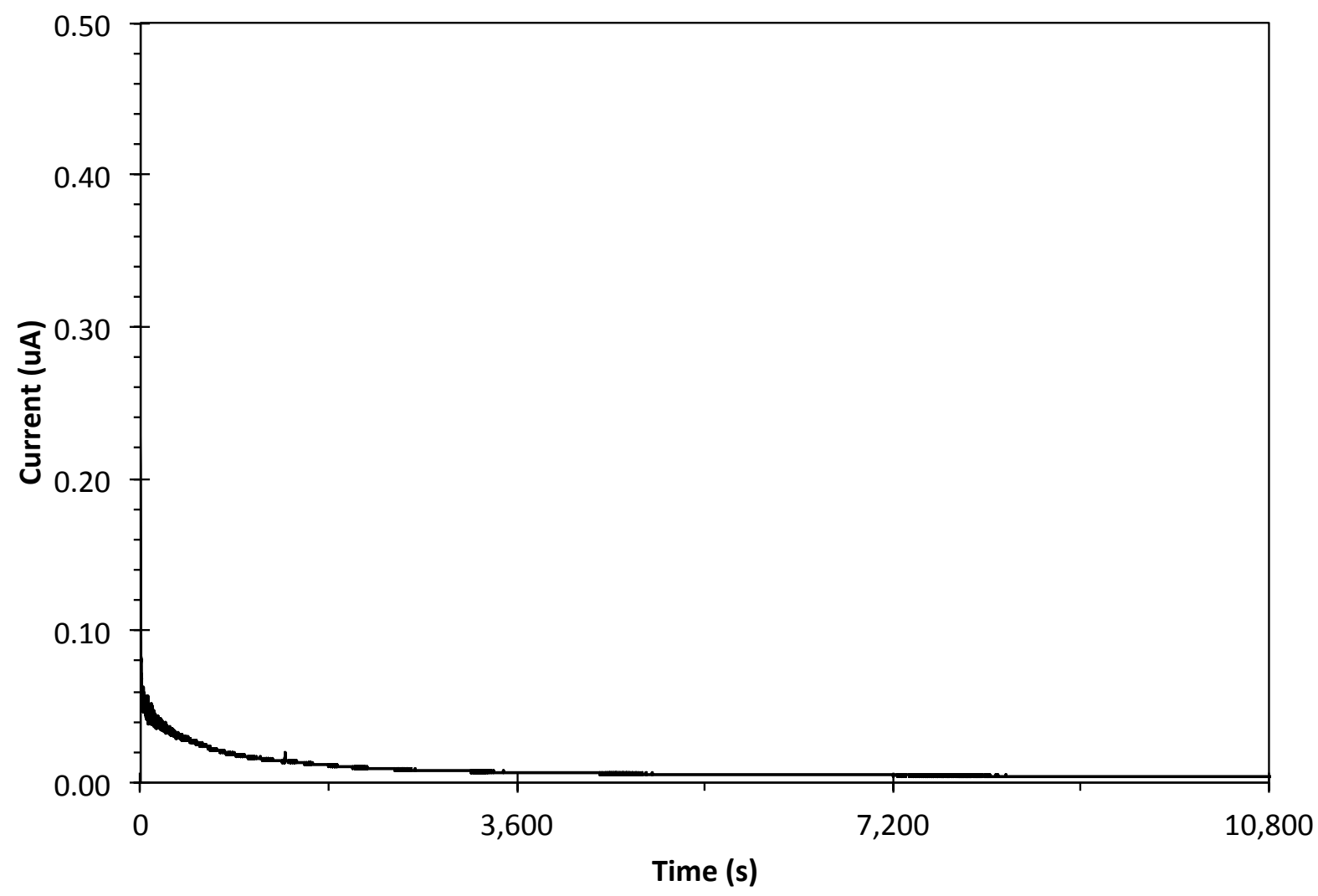

Figure S28. Controlled-potential electrolysis of $0.3 \mathrm{M}$ isopropanol and $0.04 \mathrm{M}$ phosphazene base $\mathrm{P}_{2}$-Et in $0.2 \mathrm{M} \mathrm{Bu}_{4} \mathrm{NBF}_{4}$ in 1:1 tetrahydrofuran:orthodifluorobenzene at $-0.7 \mathrm{~V}_{\text {versus }} \mathrm{Fc}^{0 /+}$. A 4.0 x $1.0 \mathrm{~cm}$ carbon cloth working electrode was used for CPE experiments. 


\section{X-Ray Absorption Spectra}

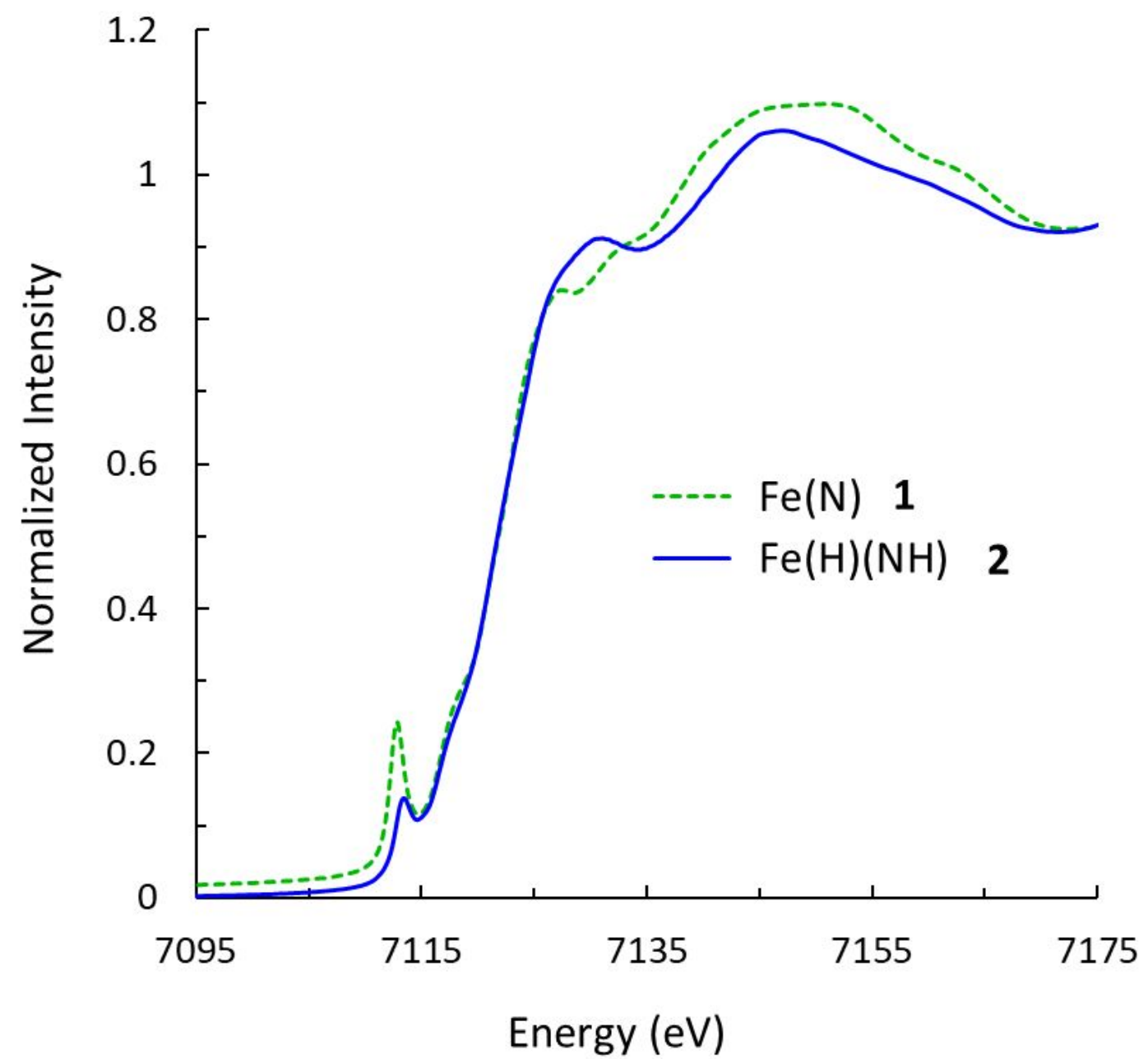

Figure S29. Fe K-edge XAS spectra of FeN 1 and $\mathrm{Fe}(\mathrm{H})(\mathrm{NH}) 2$ showing the XANES region. 
EXAFS FEFF Best Fits

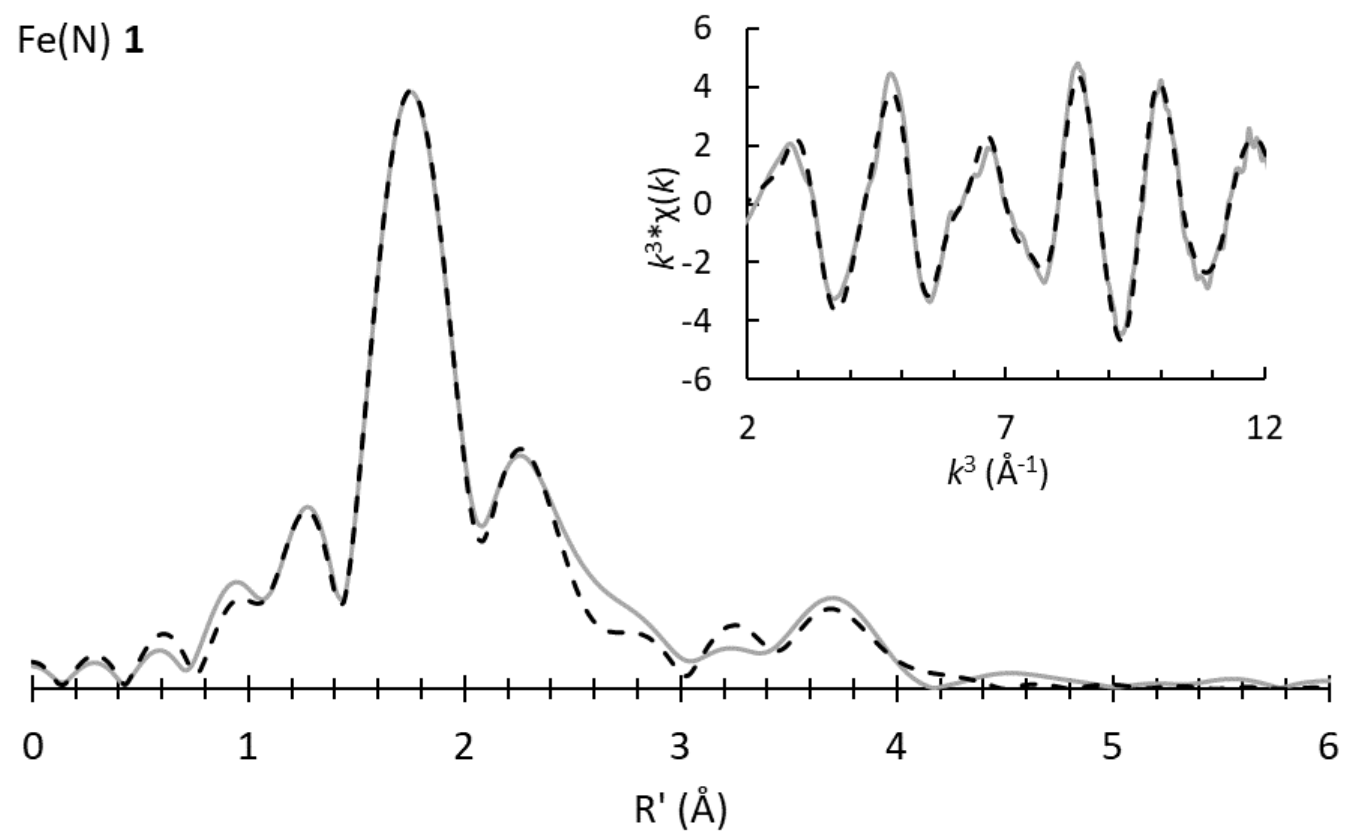

Figure S30. Non-phase shift corrected Fourier transforms of the Fe K-edge EXAFS data for FeN 1 (gray -) and their corresponding fits (black ---). Inset shows the EXAFS region and their corresponding fits.

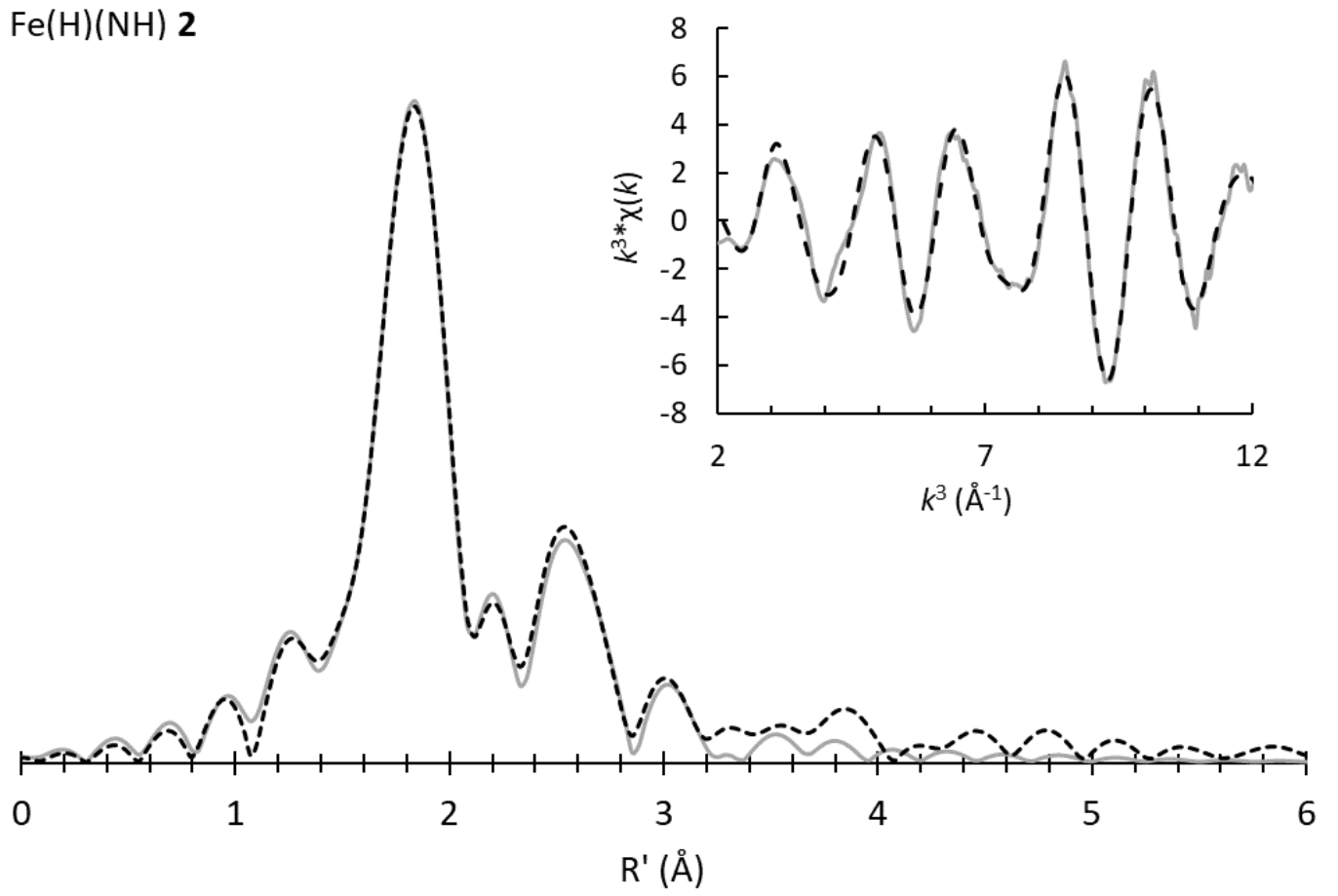

Figure S31. Non-phase shift corrected Fourier transforms of the Fe K-edge EXAFS data for $\mathrm{Fe}(\mathrm{H})(\mathrm{NH}) 2$ (gray -) and their corresponding fits (black ---). Inset shows the EXAFS region and their corresponding fits. 
Table S1. Fe K-edge EXAFS Curve-Fitting Results for FeN 1 and $\mathrm{Fe}(\mathrm{H})(\mathrm{NH}) 2$.

\begin{tabular}{|c|c|c|c|c|c|}
\hline Complex & Coordination/Path & $\mathrm{R}(\AA)^{a}$ & $\sigma^{2}\left(\AA^{2}\right)^{b}$ & $\Delta \mathrm{E}_{0}(\mathrm{eV})$ & $F^{c}$ \\
\hline \multirow{6}{*}{ FeN 1} & $1 \mathrm{Fe}-\mathrm{CO}$ & 1.70 & 264 & \multirow{6}{*}{5.91} & \multirow{6}{*}{0.15} \\
\hline & $1 \mathrm{Fe}-\mathrm{N}$ & 2.12 & 215 & & \\
\hline & $2 \mathrm{Fe}-\mathrm{P}$ & 2.17 & 162 & & \\
\hline & $2 \mathrm{Fe}-\mathrm{O}-\mathrm{C}$ & 2.90 & 230 & & \\
\hline & $2 \mathrm{Fe}-\mathrm{C}^{\mathrm{ipr}}$ & 3.44 & 223 & & \\
\hline & $2 \mathrm{Fe}-\mathrm{C}^{\mathrm{ipr}}$ & 3.54 & 256 & & \\
\hline \multirow{5}{*}{$\mathrm{Fe}(\mathrm{H})(\mathrm{NH}) 2$} & $1 \mathrm{Fe}-\mathrm{CO}$ & 1.70 & 70 & \multirow{5}{*}{-0.79} & \multirow{5}{*}{0.07} \\
\hline & $1 \mathrm{Fe}-\mathrm{N}$ & 1.83 & 70 & & \\
\hline & $2 \mathrm{Fe}-\mathrm{P}$ & 2.17 & 70 & & \\
\hline & $2 \mathrm{Fe}-\mathrm{O}-\mathrm{C}$ & 2.92 & 187 & & \\
\hline & Fe-P-P & 4.46 & 308 & & \\
\hline
\end{tabular}

${ }^{a}$ The estimated standard deviations for the distances are in order of $\pm 0.02 \AA .{ }^{b}$ The $\sigma^{2}$ values are multiplied by $10^{5}$. A / indicates that the $\mathrm{R}$ and $\sigma^{2}$ value was linked to that of the path reported directly above. ${ }^{c}$ Error is given by $\left[\Sigma\left[\left(\chi_{\text {obsd }}-\chi_{\text {calcd }}\right)^{2} k^{6}\right] /\left(\mathrm{N}_{\text {data }}-\mathrm{N}_{\text {var }}\right)\right]$. The $\mathrm{S}_{0}{ }^{2}$ factor was set at 1 . 


\section{DFT Calculations}

DFT calculations were performed at the TPSS/def2-TZVPP (Fe); def2-TZVP level of theory. Calculations were performed in a dielectric continuum using the conductor like screening model (COSMO) ${ }^{61}$ with the dielectric properties of tetrahydrofuran. Starting guess geometries were obtained from the respective crystal structures and modified appropriately where needed. Time-dependent (TD)-DFT calculations were performed with the electronic structure program ORCA to calculate the energies and intensities of the Fe $\mathrm{K}$ pre-edges. The tight convergence criterion was imposed on all calculations. The calculated energies and intensities are derived psuedo-voigt line profiles (Gaussian contribution of 0.5), generated using the MultiWFN code, broadened with half-widths of $0.6 \mathrm{eV}$ to account for core-hole lifetime and instrument resolution. The calculated pre-edge energy positions were linearly scaled to match the experimental spectra. This is generally the case with core level TD-DFT calculations since DFT does not describe core potentials accurately, resulting in the core levels being too high in energy relative to the valence levels. The TD-DFT results were compared with experimental data to judge the efficacy of the DFT calculation.

Reduction potentials for relevant species were calculated via optimization of the oxidized and reduced forms of the complex of interest. Frequency calculations were perfomed to confirm the presence of a true minima and to obtain thermodynamic parameters. The reduction potentials were calibrated to the ferrocene/ferrocenium couple and the cobaltocene/colbaltocenium couple (Table S3). The comparison of experimentally derived and computationally derived reduction potentials shows excellent agreement (Figure S33). Bond dissociation free energies (BDFEs) were calculated via optimization of the species of interest and its H-atom abstracted variant. Frequent calculations were performed to confirm the presence of a true minima and to obtain thermodynamic parameters. BDFE values were then calibrated by calculating the $\Delta \mathrm{G}_{\mathrm{rxn}}$ for $\mathrm{H}$ atom exchange with a series of organic species with known BDFEs (TEMPOH, phenol, 2,4,6tertbutylphenol, aniline). $\mathrm{p} K_{\mathrm{a}}$ values were obtained via application of the Bordwell equation $\left(\mathrm{BDFE}=1.37 \mathrm{p} K_{\mathrm{a}}-23.06 \mathrm{E}^{\mathrm{o}}+C_{\mathrm{G}}\right)$ and the DFT calculated $\mathrm{BDFE}$ and $\mathrm{E}^{\mathrm{o}}$ values of relevance. We note that the lack of a complete and reliable suite of thermochemical constants in THF limits the accuracy of $\mathrm{p} K_{\mathrm{a}}$ calculations on transition metal complexes. Nonetheless, the error using this approach (ca. $1.5 \mathrm{p} K_{\mathrm{a}}$ units) suggests that the values calculated are sufficiently accurate for the 
analysis presented in this work. For further accuracy, relative $\mathrm{p} K_{\mathrm{a}}$ values are rely upon when possible.

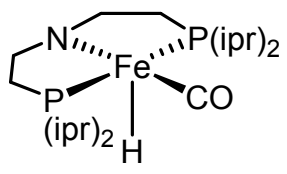

$\mathrm{Fe}(\mathrm{N})(\mathrm{H}) 1$

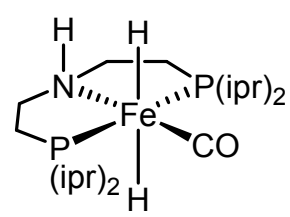

trans- $\mathrm{Fe}(\mathrm{NH})(\mathrm{H})_{2} 2$

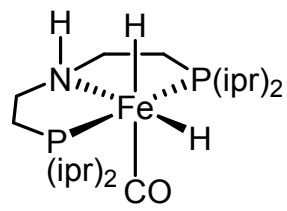

cis- $\mathrm{Fe}(\mathrm{NH})(\mathrm{H})_{2}-\mathbf{A}$

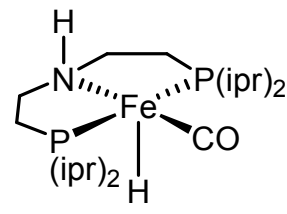

$\mathrm{Fe}(\mathrm{NH})(\mathrm{H})$

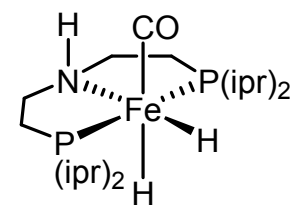

cis- $\mathrm{Fe}(\mathrm{NH})(\mathrm{H})_{2}-\mathrm{B}$

Figure S32. Structures and labels used for DFT and TD-DFT calculations shown in Table S2.

Table S2. Comparison of Crystallographic, EXAFS Derived and DFT Predicted Bond Lengths

\begin{tabular}{lccc|cc}
\hline & \multicolumn{3}{c|}{ FeN 1 } & \multicolumn{2}{c}{ Fe(H)(NH) 2 } \\
& XRD & EXAFS & DFT & EXAFS & DFT \\
\hline $\mathrm{Fe}-\mathrm{P}$ & 2.190 & 2.17 & 2.197 & 2.17 & 2.188 \\
$\mathrm{Fe}-\mathrm{N}$ & 2.175 & 2.197 & & 2.186 \\
$\mathrm{Fe}-\mathrm{CO}$ & 1.857 & 1.83 & 1.860 & 2.12 & 2.109 \\
$\mathrm{Fe}-\mathrm{H}$ & 1.732 & 1.70 & 1.726 & 1.70 & 1.708 \\
$\mathrm{~N}-\mathrm{H}$ & $\mathrm{n} / \mathrm{a}$ & $\mathrm{n} / \mathrm{a}$ & 1.503 & $\mathrm{n} / \mathrm{d}$ & 1.561 \\
& $\mathrm{n} / \mathrm{a}$ & $\mathrm{n} / \mathrm{a}$ & $\mathrm{n} / \mathrm{a}$ & $\mathrm{n} / \mathrm{d}$ & 1.021 \\
\hline
\end{tabular}


Table S3. Calculated Oxidation Potentials $\left(\mathrm{E}_{\mathrm{ox}}{ }^{\mathrm{calc}}\right)$ and BDFEs $\left(\mathrm{BDFE}^{\mathrm{calc}}\right)$ for Selected Species.

\begin{tabular}{|c|c|c|c|c|}
\hline Entry & & $\begin{array}{l}\mathrm{E}_{\mathrm{ox}}^{\text {calc }} \\
\left(\mathrm{V} \text { vs Fc } \mathrm{Fc}^{+/ 0}\right)\end{array}$ & 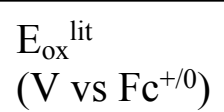 & $\begin{array}{l}\mathrm{BDFE}^{\text {calc }} \\
(\mathrm{kcal} / \mathrm{mol})\end{array}$ \\
\hline 1 & $\mathrm{Cp}_{2} \mathrm{Fe}$ & 0.0 (def.) & 0.0 (def.) & -- \\
\hline 2 & $\mathrm{Cp}_{2} \mathrm{Co}$ & -1.49 & -1.46 & -- \\
\hline 3 & $\mathrm{Fe}(\mathrm{N})(\mathrm{H}) 1$ & -0.35 & -0.34 & -- \\
\hline 4 & trans $-\mathrm{Fe}(\mathrm{NH})(\mathrm{H})_{2} 2$ & -0.68 & -0.74 & $\begin{array}{l}71.1(\mathrm{~N}-\mathrm{H}) \\
66.4(\mathrm{Fe}-\mathrm{H})\end{array}$ \\
\hline 5 & trans $-\mathrm{Fe}(\mathrm{NH})(\mathrm{H})_{2}^{+}$ & $\mathrm{n} / \mathrm{a}$ & $\mathrm{n} / \mathrm{a}$ & $\begin{array}{l}62.9(\mathrm{~N}-\mathrm{H}) \\
44.7(\mathrm{Fe}-\mathrm{H})\end{array}$ \\
\hline 6 & $\mathrm{Fe}(\mathrm{NH})(\mathrm{H})$ & -1.67 & $\mathrm{n} / \mathrm{a}$ & $41.3(\mathrm{~N}-\mathrm{H})$ \\
\hline 7 & $\mathrm{Fe}(\mathrm{N})(\mathrm{H})_{2}$ & -1.10 & $\mathrm{n} / \mathrm{a}$ & $36.6(\mathrm{Fe}-\mathrm{H})$ \\
\hline 8 & $c i s-\mathrm{Fe}(\mathrm{NH})(\mathrm{H})_{2}-\mathrm{A}$ & -0.69 & $\mathrm{n} / \mathrm{a}$ & $\begin{array}{l}63.5(\mathrm{~N}-\mathrm{H}) \\
63.3\left(\mathrm{Fe}-\mathrm{H}_{\mathrm{eq}}\right) \\
62.2\left(\mathrm{Fe}-\mathrm{H}_{\mathrm{ax}}\right)\end{array}$ \\
\hline 9 & $c i s-\mathrm{Fe}(\mathrm{NH})(\mathrm{H})_{2}-\mathrm{B}$ & -0.73 & $\mathrm{n} / \mathrm{a}$ & $\begin{array}{l}63.1(\mathrm{~N}-\mathrm{H}) \\
64.1\left(\mathrm{Fe}-\mathrm{H}_{\mathrm{eq}}\right) \\
65.7\left(\mathrm{Fe}-\mathrm{H}_{\mathrm{ax}}\right)\end{array}$ \\
\hline
\end{tabular}

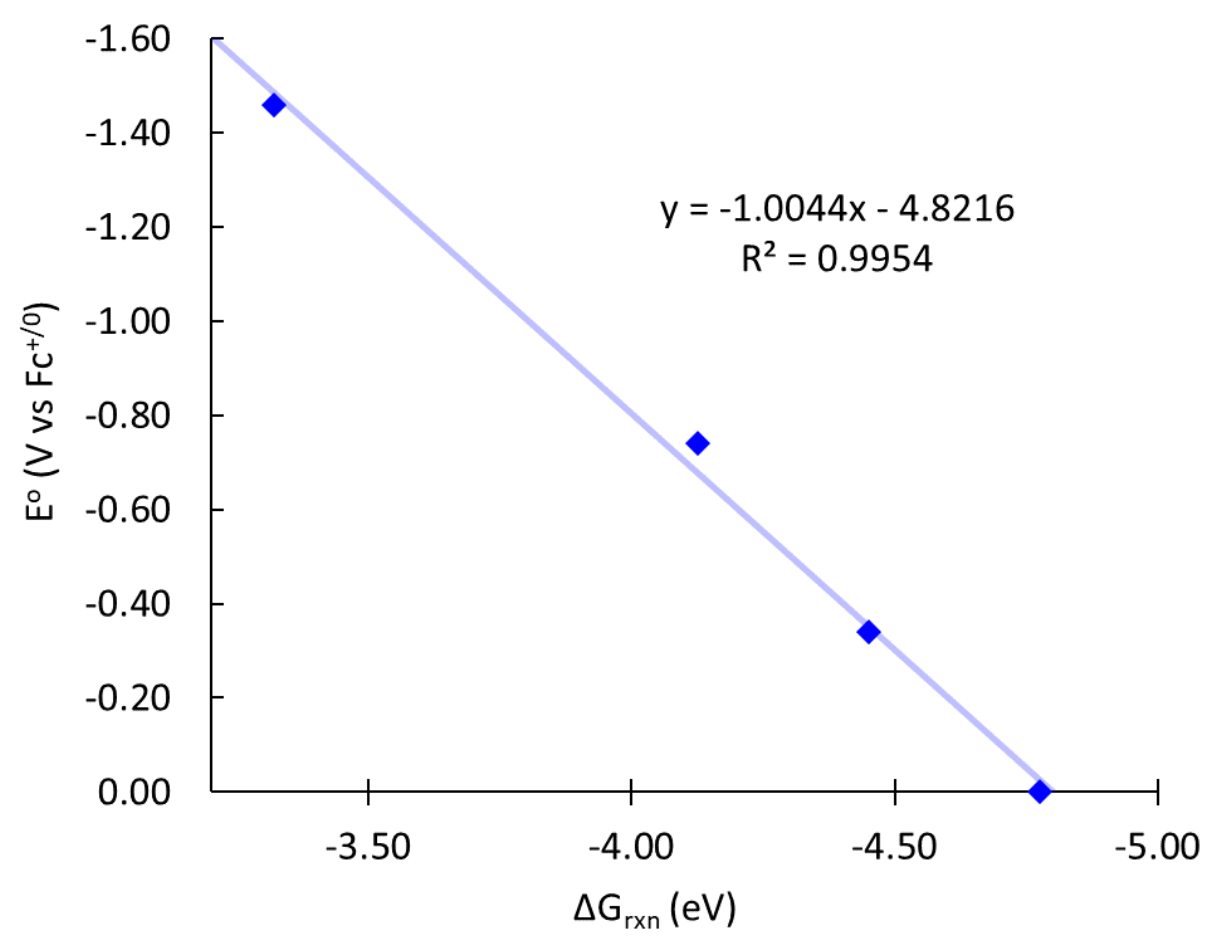

Figure S33. Plot of calculated $\Delta \mathrm{G}_{\mathrm{rxn}}(\mathrm{eV})$ vs literature $\mathrm{E}_{\text {ox }}^{\mathrm{o}}\left(\mathrm{V} v \mathrm{vs} \mathrm{Fc}^{+/ 0}\right)$ for Table $\mathrm{S} 2$ entries 1-4. 

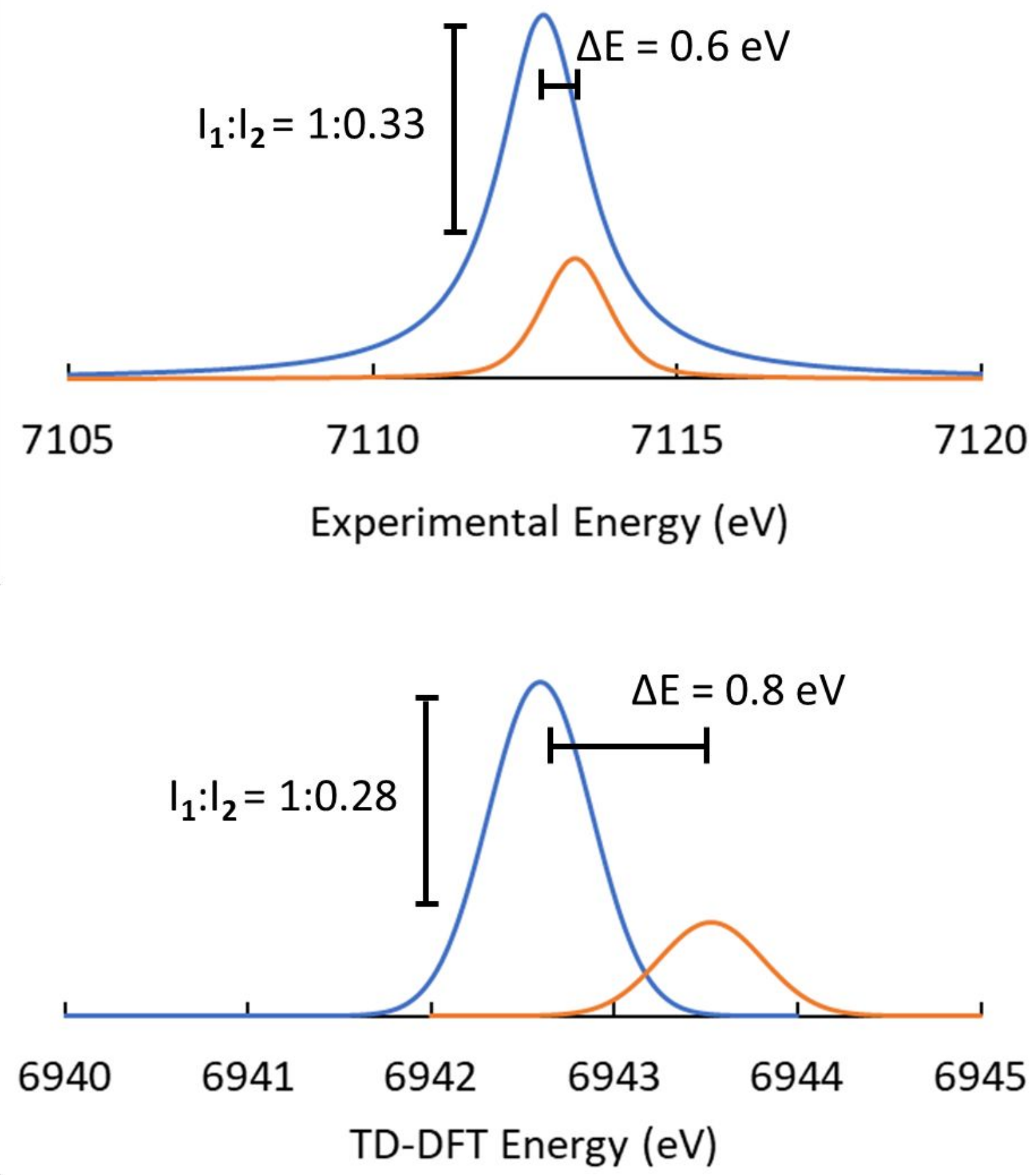

Figure S34. Comparison of TD-DFT calculated pre-edge features to experimentally derived FeK-pre-edge features. 